 \\ -
}

$\therefore$ 
The Dibner Library of the History of

Science and Technology

SMITHSONIAN INSTITUTION LIBRARIES

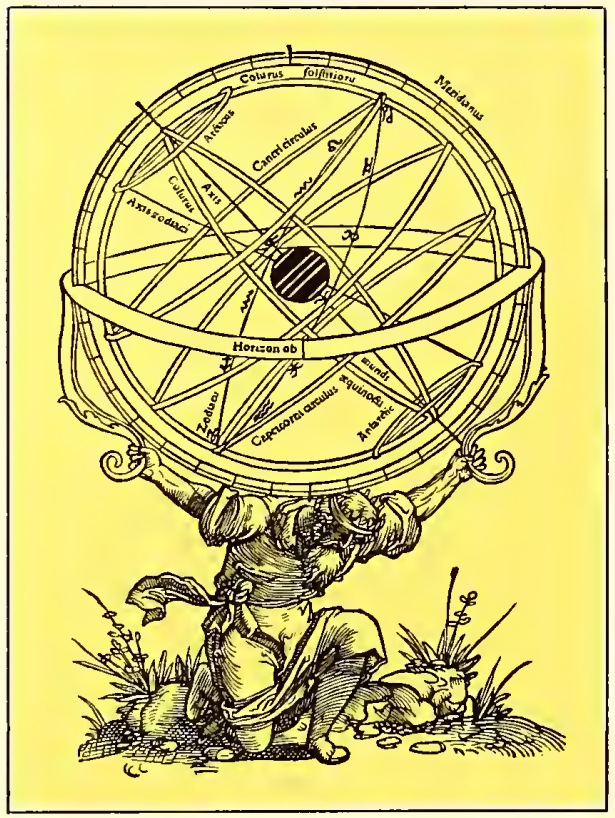



VIII. Experimental Researches in Electricity.-Thirteenth Series. By MichaEL Faraday, Esq., D.C.L. F.R.S. Fullerian Prof. Chem. Royal Institution, Corr. Memb. Royal and Imp. Acadd. of Sciences, Paris, Petersburgh, Florence, Copenhagen, Berlin, \&c. \&c.

Received February 22,--Read March 15, 1838.

§. 18. On Induction (continued). I ix. Disruptive discharge (continued)Peculiarities of positive and negative discharge either as spark or brush-Glow discharge-Dark discharge.- $\mathrm{T}$. Convection, or carrying discharge. Iा xi. Relation of a vacuum to electrical phenomena. §. 19. Nature of the electrical current.

T ix. Disruptive discharge (continued).

1480. LET us now direct our attention to the general difference of the positive and negative disruptive discharge, with the object of tracing, as far as possible, the cause of that difference, and whether it depends on the charged conductors principally, or on the interposed dielectric ; and as it appear's to be great in air and nitrogen (1476.), let us observe the phenomena in air first.

1481. The general case is best understood by a reference to surfaces of considerable size rather than to points, which involve (as a secondary effect) the formation of currents (1562.). My investigation, therefore, was carried on with balls and terminations of different diameters, and the following are some of the principal results.

1482. If two balls of very different dimensions, as for instance one, half an inch, and the other three inches, in diameter, be arranged at the ends of rods so that either can be electrified by a machine and made to discharge by sparks to the other, which is at the same time uninsulated; then, as is well known, far longer sparks are obtained when the small ball is positive and the large ball negative, than when the small ball is negative and the large ball positive. In the former case, the sparks are 10 or 12 inches in length; in the latter an inch or an inch and a half only.

1483. But previous to the description of further experiments, I will niention two words, for which with many others I am indebted to a friend, and which I think it would be expedient to introduce and use. It is important in ordinary inductive action, to distinguish at which charged surface the induction originates and is sustained: i. e. if two or more metallic balls, or other masses of matter, are in inductive relation, to express which are charged originally, and which are brought by them into the 
opposite electrical condition. I propose to call those bodies which are originally charged, inductric bodies; and those which assume the opposite state, in consequence of the induction, inducteous bodies. This distinction is not needful because there is any difference between the suins of the inductric and the inducteous forces; but principally because, when a ball $\mathbf{A}$ is inductric, it not merely brings a ball $\mathbf{B}$, which is opposite to it, into an inducteous state, but also many other surrounding conductors, though some of them may be a considerable distance off, and the consequence is, that the balls do not bear the same precise relation to each other when, first the one, and then the other, is inade the inductric ball; though, in each case, the same ball be made to assume the same state.

1484. Another liberty which I may also occasionally take in language I will explain and limit. It is that of calling a particular spark or brush, positive or negative, according as it may be considered as originating at a positive or a negative surface. We speak of the brush as positive or negative when it shoots ont from surfaces previonsly in those states; and the experiments of Mr. Wheatstone go to prove that it really begins at the charged surface, and from thence extends into the air (1437. 1438.) or other dielectric. According to my view, sparks also originate or are determined at one particular spot (1370.), namely, that where the tension first rises up to the maximum degree; and when this can be detcrmined, as in the simultaneous use of large and small balls, in which case the discharge begins or is determined by the latter, I would call that discharge which passes at once, a positive spark, if it was at the positive surface that the maximum intensity was first obtained, or a negative spark, if that necessary intensity was first obtained at the negative surface.

1485. An apparatus was arranged, as in fig. 15. (Plate III.): A and B, were brass balls of very different diameters attached to metal rods, moving through sockets on insulating pillars, so that the distance between the balls could be varied at pleasure. The large ball A, 2 inches in diameter, was connected with an insulated brass conductor, which could be rendered positive or negative directly from a cylinder machine: the small ball $\mathrm{B}, 0.25$ of an inch in diametcr, was connected with a discharging train (292.) and perfectly uninsulated. 'The brass rods sustaining the balls were $0 \cdot 2$ of an inch in thickness.

1486. When the large ball was positive and inductric (1483.), negative sparks occurred until the interval was 0.49 of an inch; then mixed brush and spark between that and 0.51 ; and from 0.52 and upwards, negative brush alone. When the large ball was made negative and inductric, then positive spark alone occurred until the interval was as great as $1 \cdot 15$ inches; spark and brush from that up to 1.55 ; and to have the positive brush alone, it required an interval of at least 1.65 inches.

1487. The balls $A$ and $B$ were now changed for each other. Then making the small ball B inductric positively, the positive sparks alone continued only up to 0.67 ; spark and brush occurred from 0.68 up to 0.72 ; and positive brush alone from 0.74 and upwards. Rendering the small ball $\mathrm{B}$ inductric and negative, negative sparks 
alone occurred up to 0.40 ; then spark and brush at 0.42 ; whilst from 0.44 and upwards the noisy negative brush alone took place.

1488. We thus find a great difference as the balls are rendered inductric or inducteous; the small ball rendered positive inducteously giving a spark nearly twice as long as that produced when it was charged positive inductrically, and a similar difference, though not, under the circumstances, to the same extent, was manifest when it was rendered negative.

1489. Another lesult is, that the small ball rendered positive gives a much longer spark than when it is rendered negative, and that the small ball rendered negative gives a brush more readily than when positive, in relation to the effect of increasing distance.

1490. When the interval was below 0.4 of an inch, so that the small ball should give sparks, whether positive or negative, I could not observe that there was any constant difference, either in their ready occurrence or the number which passed in a given time. But when the interval was such that the small ball when negative gave a brush, then the discharges from it, as separate negative brushes, were far more numerous than the corresponding discharges from it when rendered positive, whether those positive discharges were as sparks or brushes.

1491. It is, therefore, evident that, when a ball is discharging electricity in the form of brisshes, the brushes are far more numerous, and each contains or carries off far less electric force when the electricity so discharged is negative, than when it is positive.

1492. In all such experiments as those described, the point of change from spark to brush is very much governed by the working state of the electrical machine and the size of the conductor connected with the discharging ball. If the machine be in strong action and the conductor large, so that much power is accumulated quickly for each discharge, then the interval is greater at which the sparks are replaced by brushes; but the general effect is the same.

1493. These results, though indicative of very striking and peculiar relations of the electric force or forces, do not show the relative degrees of charge which the small ball acquires before discharge occur's, i. e. they do not tell whether it acquires a higher condition in the negative, or in the positive state, immediately preceding that discharge. To illustrate this important point I arranged two places of discharge as represented, fig. 16. A and D, are brass balls 2 inches in diameter, $\mathrm{B}$ and $\mathrm{C}$ are smaller brass balls 0.25 of an inch in diameter' the forks $\mathrm{L}$ and $\mathrm{R}$ supporting them were of brass wire 0.2 of an inch in diameter: the space between the large and small ball on the same fork was 5 inches, that the two pluces of discharge $n$ and $o$ might be sufficiently removed from each other's influence. The fork $L$ was connected with a projecting cylindrical conductor, which could be rendered positive or negative at pleasure, by an electrical machine, and the fork $\mathbf{R}$ was attached to another conductor, but thrown into an uninsulated state by connection with a dis- 
charging train. The two intervals or places of discharge $n$ and $o$ could be varied at pleasure, their extent being measured by the occasional introduction of a diagonal scale. It is evident, that, as the balls $A$ and $B$ connected with the same conductor are always charged at once, and that discharge may take place to either of the balls connected with the discharging train, the intervals of discharge $n$ and $o$ may be properly compared to each other, as respects the influence of large and small balls when charged positively and negatively in air.

1494. When the intervals $n$ and $o$ were each made $=0.9$ of an inch, and the balls $\mathrm{A}$ and $\mathrm{B}$ inductric positively, the discharge was all at $n$ from the small ball of the conductor to the large ball of the discharging train, and mostly by positive brush, though once by a spark. When the balls A and B were made inductric negatively, the discharge was still from the same small ball, at $n$, by a constant negative brush.

1495. I diminished the intervals $n$ and $o$ to $0 \cdot 6$ of an inch. When A and B were inductric positively, all the discharge was at $n$ as a positive brush: when $\mathrm{A}$ and $\mathrm{B}$ were inductric negatively, still all the discharge was at $n$, as a negative brush.

1496. The facility of discharge at the positive and negative small balls, thercfore, did not appear to bc very different. If a difference had existed, there were always two small balls, one in each state, that the discharge might happen at that most favourable to the effect. The only difference was, that one was in the inductric, and the other in the inducteous state, but whichever happened for the time to be in that state, whether positive or negative, had the advantage.

1497. To counteract this interfering influence, I made the interval $n=0.79$ and interval $o=0.58$ of an inch. Then, when the balls A and B were inductric positive, the discharge was about equal at the two intervals. When, on the other hand, the balls $A$ and B were inductric negative, there was discharge, still at both, but most at $n$, as if the small ball negative could discharge a little easier than the same ball positive.

1498. The small balls and terminations used in these and similar experiments may very correctly be compared, in their action, to the same balls and ends when electrified in free air at a much greater distance from conductors, than they were in those cases from each other. In the first place, the discharge, even when as a spark, is, according to my view, determined, and, so to speak, begins at a spot on the surface of the small ball (1374.), occurring when the intensity there has risen up to a certain maximum limiting degree (1370.); this determination of discharge at a particular spot first, being easily traced from the spark into the brush, by increasing the distance, so as, at last, even to render evident the time which is necessary (1436. 1438.). In the next place, the large balls which I have used might be replaced by larger balls at a still greater distance, and so, by successive degrees, may be considered as passing into the sides of the rooms; these being under general circumstances the inducteous bodies, whilst the small ball rendered either positive or negative is the inductric body.

1499. But, as has long been recognised, the small ball is only a blunt end, and, electrically speaking, a point only a small ball; so that when a point or blunt end is 
throwing out its brushes into the air, it is acting exactly as the small balls have acted in the experiments already described, and by virtue of the same properties and relations.

1500. It may very properly bc said with respect to the expcriments, that the large negative ball is as essential to the discharge as the sinall positive ball, and also that the large negative ball shows as much superiority over the large positive ball (which is inefficient in causing a spark from its opposed small negative ball) as the small positive ball does over the small negative ball; and probably when we understand the real cause of the difference, and refer it rather to the condition of the particles of the dielectric than to the sizes of the conducting balls, we may find much inportance in such an observation. But for the present, and whilst engaged in investigating the point, we may admit, what is the fact, that the forces are of higher intensity at the surfaces of the smaller balls than at those of the larger (1372. 1374.); that the former, therefore, determinc the discharge, by first rising up to that exalted condition which is necessary for it; and that, whether brought to this condition by induction towards the walls of a room or the large balls I have used, thcse may fairly be compared one with the other in their influence and actions.

1501. The conclusions I arrive at are: first, that when two cqual small conducting surfaccs equally placed in air are electrified, one positively and the other negatively, that which is negative can discharge to the air at a tension a little lower than that required for the positive ball: sccond, that when discharge does take place, much more passes at each time from the positive than from the negative surface (1491.). The last conclusion is very abundantly proved by the optical analysis of the positive and negative bruslies already described (1468.), the latter set of discharges being found to recur five or six times oftener than the former*.

1502. If, now, a small ball be madc to give brushes or brushy sparks by a powerful machine, we can, in some measure, understand and relate the difference perceived when it is rendered positive or negative. It is known to give when positive a much larger and more powerful spark than when negative, and with greater facility (1482.); in fact, the spark, although it takes away so much more electricity at once, commences at a tension higher only in a small degree, if at all. On the other hand, if rendered negative, though discharge may commence at a lower degree, it continues but for a very short period, very little electricity passing away each time. 'These circumstances are directly related, for the extcnt to which the positive spark can reach, and the size and extent of the positive brush, are consequences of the capability which exists of much electricity passing off at onc discharge from the positive surface (1468. 1501.).

1503. But to relate these effects only to the form and size of the conductor, would, according to my notion of induction, be a very imperfect mode of viewing the whole

* A very excellent mode of examining the relation of small positive and negative surfaces would be by the use of drops of gum water, solutions, or other liquids. See onwards (1581. 1593.).

MDCCCXXXviII. 
question (1523.). I expect that the effects are due altogether to the mode in which the particles of the interposed dielectric polarize, and I have already given some experimental indications of the differences presented by different dielectrics in this respect (1475. 1476.). The modes of polarization, as I shall have occasion hereafter to show, may be very diverse in different dielectrics. With respect to common air, what seems to be the consequence of a superiority in the positive force at the surface of the small ball, may be due to the more exalted condition of the negative polarity of the particles of air, or of the nitrogen in it (the negative part being, perhaps, more compressed, whilst the positive part is more diffuse, or vice versa) ; for such a condition could determine certain effects at the positive ball which would not take place to the same degree at the negative ball, just as well as if the positive ball had possessed some special and independent power of its own.

1504. That the effects are more likely to be dependent upon the dielectric than the ball, is supported by the character of the two discharges. If a small positive ball be throwing off brushes with ramifications ten inches long, how can the ball affect that part of a ramification which is five inches from it? Yet the portion beyond that place has the same character as that preceding it, and no doubt has that character impressed by the same general principle and law. Looking upon the action of the contiguous particles of a dielectric as fully proved, I see, in such a ramification, a propagation of discharge from particle to particle, each doing for the one next it what was done for it by the preceding particle, and what was done for the first particle by the charged metal against which it was situated.

1505. With respect to the general condition and relations of the positive and negative brushes in dense or rare air, or in other media and gases, if they are produced at different times and places, they are of course independent of each other. But when they are produced from opposed ends or balls at the same time, in the same vessel of gas (1470. 1477.), they are frequently related; and circumstances may be so arranged that they shall be isochronous, occurring in equal numbers in equal times; or shall occur in multiples, i. e. with two or three negatives to one positive; or shall alternate, or be quite irregular. All these variations I have witnessed; and when it is considered that the air in the vessel, and also the glass of the vessel, can take a momentary charge, it is easy to comprehend their general nature and cause.

1506. Similar experiments to those in air (1485. 1493.) were made in different gases, the results of which $I$ will describe as briefly as possible. The apparatus is represented fig. 17. consisting of a bell-glass eleven inches in diameter at the widest part, and ten and a half inches high up to the bottom of the neck. The balls are lettered, as in fig. 16, and are in the same relation to each other; but $\mathbf{A}$ and $\mathbf{B}$ were on separate sliding wires, which, however, were generally joined by a cross wire, $w$, above, and that connected with the brass conductor, which received its positive or negative charge from the machine. The rods of $A$ and $B$ were graduated at the part moving through the stuffing-box, so that the application of a diagonal scale applied there, told what was 
the distance between these balls and those beneath them. As to the position of the balls in the jar, and their relation to each other, $\mathrm{C}$ and $\mathrm{D}$ were three and a quarter inches apart, their height above the pump platc five inches, and the distance between any of the balls and the glass of the jar one and three quarter inches at least, and generally more. The balls $A$ and $D$ were two inches in diameter, as before (1493.): the balls $\mathrm{B}$ and $\mathrm{C}$ only 0.15 of an inch in diameter.

Another apparatus was occasionally used in connection with the one just described, being an open discharger (fig. 18.), by which a comparison of the discharge in air and that in gases could be obtained. The balls $\mathbf{E}$ and $\mathbf{F}$, each 0.6 of an inch in diameter, were connected with sliding rods and other balls, and were insulated. When used for comparison, the brass conductor was associated at the same time with the balls A and B of figure 17 and ball $\mathrm{E}$ of this apparatus (fig. 18.); whilst the balls C, D and F were connected with the discharging train.

1507. I will first tabulate the results as to the restraining power of the gases over discharge. The balls A and C (fig. 17.) were thrown out of action by distance, and the effects at $\mathbf{B}$ and $\mathrm{D}$, or the interval $n$ in the gas, compared with those at the interval $p$ in the air, between $\mathbf{E}$ and $\mathbf{F}$ (fig. 18.). The Table sufficiently explains itself. It will be understood, that all discharge was in the air, when the interval there was less than that expressed in the first or third columns of figures; and all the discharge in the gas, when the interval in air was greater than that in the second or fourth column of figures. At intermediate distances the discharge was occasionally at both places, i. e. sometimes in the air, sometimes in the gas.

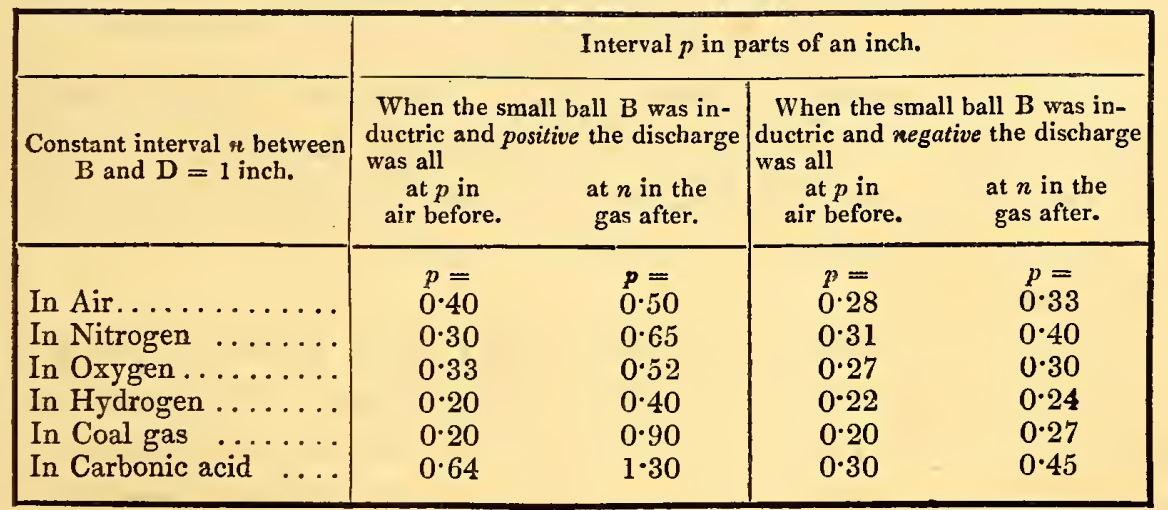

1508. These results are the same generally, as far as they go, as those of the like nature in the last series (1388.), and confirm the conclusion that different gases restrain discharge in very different proportions. They are probably not so good as the former ones, for the glass jar not being varnished, acted irregularly, sometimes taking a certain degree of charge as a non-conductor, and at other times acting as a conductor in the conveyance and derangement of that charge. Another cause of difference in the ratios is, no doubt, the relative sizes of the discharge balls in air ; in the former case they were of very different size, here they were alike. 
1509. In future experiments intended to have the character of accuracy, the influence of these circumstances ought to be ascertained, and, above all things, the gases themselves ought to be contained in vessels of metal, and not of glass.

1510. The next set of results are those obtained when the intervals $n$ and $o$ (fig. 17.) were made equal to each other, and relate to the greater facility of discharge at the small ball, when rendered positive or negative (1493.).

1511. In air, with the intervals $=0.4$ of an incl, $A$ and $B$ being inductric and positive, discharge was nearly equal at $n$ and $o$; when $\mathrm{A}$ and $\mathrm{B}$ were inductric and negative, the discharge was mostly at $n$ by negative brush. When the intervals were $=0.8$ of an inch, with $\mathrm{A}$ and $\mathrm{B}$ inductric positively, all discharge was at $n$ by positive brush; with $\mathrm{A}$ and $\mathrm{B}$ inductric negatively, all the discharge was at $\boldsymbol{n}$ by a negative brush. It is doubtful, therefore, from these results, whether the negative ball has any greater facility than the positive.

1512. Nitrogen.-Intervals $n$ and $o=0.4$ of an inch : A, B inductric positive, discharge at both intervals, most at $n$, by positive sparks; $\mathrm{A}, \mathrm{B}$ inductric negative, discharge equal at $n$ and $o$. The intervals made $=0.8$ of an inch: A, B inductric positive, discharge all at $\boldsymbol{n}$ by positive brush ; A, B inductric negative, discharge most at $o$ by positive brush. In this gas, therefore, though the difference is not decisive, it would seem that the positive small ball caused the most ready discharge.

1513. Oxygen.-Intervals $n$ and $o=0.4$ of an inch: A, B inductric positive, discharge nearly equal; inductric negative, discharge mostly at $n$ by negative brush. Made the intervals $=0.8$ of an inch : A, B inductric positive, discharge at $n$ and $o$; inductric negative, discharge all at $o$ by negative brush. So here the negative small ball seems to give the most ready discharge.

1514. Hydrogen.-Intervals $n$ and $o=0.4$ of an inch: A, B inductric positive, discharge nearly equal; inductric negative, discharge mostly at 0 . Intervals $=0.8$ of an inch: $\mathrm{A}$ and $\mathrm{B}$ inductric positive, discharge mostly at $n$, as positive brush ; inductric negative, discharge mostly at $o$, as positive brush. Here the positive discharge seems most facile.

1515. Coal gas. $-n$ and $o=0.4$ of an inch: A, B inductric positive, discharge nearly all at $o$ by negative spark: A, B inductric negative, discharge nearly all at $n$ by negative spark. Intervals $=0.8$ of an inch, and $A, B$ inductric positive, discharge mostly at $o$ by negative brush : A, B inductric negative, discharge all at $n$ by negative brush. Here the negative discharge most facile.

1516. Carbonic acid gas.- $n$ and $o=0.4$ of an inch : A, B inductric positive, discharge nearly all at $o$, or negative: $\mathrm{A}, \mathrm{B}$ inductric negative, discharge nearly all at $n$, or negative. Intervals $=0.8$ of an inch : $\mathrm{A}, \mathrm{B}$ inductric positive, discharge mostly at $o$, or negative: $\mathrm{A}, \mathrm{B}$ inductric negative, discharge all at $n$, or negative. In this case the negative had a decided advantage in facility of discharge.

1517. Thus, if we may trust this form of experiment, the negative small ball has a decided advantage in facilitating disruptive discharge over the positive small ball in 
some gases, as in carbonic acid gas and coal gas (1399.), whilst in others that conclusion seems more doubtful; and in other's, again, there seems a probability that the positive small ball may be superior. All these results were obtaincd at very nearly the same pressure of the atmosphere.

1518. I made some experiments in these gases whilst in the air jar (fig. 17.), as to the change from spark to brush, analogous to those in the open air already described (1486. 1487.). I will give, in a Table, the results as to when brush began to appear mingled with the spark; but the after results were so varied, and the nature of the discharge in different gases so different, that to insert the results obtained without further investigation, would be of little use. At intervals less than those expressed the discharge was always by spark.

\begin{tabular}{|c|c|c|c|c|}
\hline & \multicolumn{2}{|c|}{ Discharge between balls B and D. } & \multicolumn{2}{|c|}{ Discharge between balls $A$ and $C$. } \\
\hline & $\begin{array}{l}\text { Small ball B } \\
\text { inductric pos. }\end{array}$ & $\begin{array}{l}\text { Small ball B } \\
\text { inductric neg. }\end{array}$ & $\begin{array}{l}\text { Large ball A } \\
\text { inductric pos. }\end{array}$ & $\begin{array}{l}\text { Large ball A } \\
\text { inductric neg. }\end{array}$ \\
\hline Air ......... & $0 \cdot 55$ & $0 \cdot 30$ & $0 \cdot 40$ & $0 \cdot 75$ \\
\hline Nitrogen..... & $0 \cdot 30$ & $0 \cdot 40$ & 0.52 & $0 \cdot 41$ \\
\hline Oxygen ... & $0 \cdot 70$ & $0 \cdot 30$ & $0 \cdot 4 \check{\jmath}$ & $0 \cdot 82$ \\
\hline Hydrogen .... & $0 \cdot 20$ & $0 \cdot 10$ & & \\
\hline Coal gas..... & $0 \cdot 13$ & $0 \cdot 30$ & $0 \cdot 30$ & $0 \cdot 14$ \\
\hline Carbonic acid.. & $0 \cdot 82$ & $0 \cdot 43$ & $1 \cdot 60$ & $\left\{\begin{array}{c}\text { above } 1.80 \text {; had } \\
\text { not space. }\end{array}\right.$ \\
\hline
\end{tabular}

1519. It is to be understood that sparks occurred at much higher intervals than these; the table only expresses that distance beneath which all discharge was as spark. Some curious relations of the different gases to discharge are already discernible, but it would be useless to consider them until illustrated by further experiments.

1520. I ought not to omit noticing here, that Professor BeLli of Milan has published a very valuable set of experiments on the relative dissipation of positive and negative electricity in the air*; he finds the latter far more ready, in this respect, than the former.

1521. I made some experiments of a similar kind, but with sustained high charges; the results were less striking than those of Signore BeLLI, and I did not consider them as satisfactory. I may be allowed to mention, in connection with the subject, an interfering effect which embarrassed me for a long time. When I threw positive electricity from a given point into the air, a certain intensity was indicated by an electrometer on the conductor connected with the point, but as the operation continued this intensity rose several degrees; then making the conductor negative with the same point attached to it, and all other things remaining the same, a certain degree of tension was observed in the first instance, which also gradually rose as the operation proceeded. Returning the conductor to the positive state, the tension was at first low, but rose as before; and so also when again made negative.

\footnotetext{
* Bibliotheque Universelle, ] 836, September, p. 152.
} 
1522. This result appeared to indicate that the point which had been giving off one electricity, was, by that, more fitted for a short time to give off the other. But on closer examination I found the whole depended upon the inductive reaction of that air, which being charged by the point, and gradually increasing in quantity before it, as the positive or negative issue was continued, diverted and removed a part of the inductive action of the surrounding wall, and thus apparently affected the powers of the point, whilst really it was the dielectric itself that was causing the change of tension.

1523. The results connected with the different conditions of positive and negative discharge will have a far greater influence on the philosophy of electrical science than we at present imagine, especially if, as I believe, they depend on the peculiarity and degree of polarized condition which the molecules of the dielectrics concerned acquire (1503.1600.). Thus, for instance, the relation of our atmosphere and the earth within it, to the occurrence of spark or brush, must be especial and not accidental. It would not else consist with other meteorological phenomena, also of course dependent on the special properties of the air, and which being themselves in harmony the most perfect with the functions of animal and vegetable life, are yet restricted in their actions, not by loose regulations, but by laws the most precise.

1524. Even in the passage through air of the voltaic current, we see the peculiarities of positive and negative discharge at the two charcoal points; and if these discharges are made to take place simultaneously to mercury, the distinction is still more remarkable.

1525. It seems very possible that the striking difference recently observed and described by my friend Professor Daniell*, namely, that when a zinc and a copper ball, the same in size, were placed respectively in copper and zinc spheres, also the same in size, and excited by electrolytes or dielectrics of the same strength and nature, the zinc ball far surpassed the zinc sphere in action, may also be connected with these phenomena; for it is not difficult to conceive how the polarity of the particles shall be affected by the circumstance of the positive surface, namely the zinc, being the larger or the smaller of the two inclosing the electrolyte. It is even possible, that with different electrolytes or dielectrics the ratio may be considerably varied, or in some cases even inverted.

\section{Glow discharge.}

1526. That form of disruptive discharge which appears as a glow (1359. 1405.), is very peculiar and beautiful: it seems to depend on a quick and almost continuous charging of the air close to, and in contact with, the conductor.

1527. Diminution of the charging surface will produce it. Thus, when a rod 0.3

* Philosophical Transactions, 1838, p. 47. 
of an inch in diameter, with a rounded termination, was rendered positive in free air, it gave fine brushes from the extremity, but occasionally these disappeared, and a quiet phosphorescent continuous glow took their place, covering the whole of the end of the wire, and extending a very small distance from the metal into the air. With a rod 0.2 of an inch in diameter the glow was more readily produced. With still smaller rods, and also with blunt conical points, it occurred still more readily; and with a fine point I could not obtain the brush in free air, but only this glow. The positive glow and the positive star are, in fact, the same.

1528. Increase of power in the machine tends to produce the glow; for rounded terminations which will give only brushes where the machine is in weak action, will readily give the glow when it is in good order.

1529. Rarefaction of the air wonderfully favours the glow phenomena. A brass ball, two and a half inches in diameter, being made positively inductric in an airpump receiver, became covered with glow over an area of two inches in diameter, when the pressure was reduced to $4 \cdot 4$ inches of mercury. By a little adjustment the ball could be covered all over with this light. Using a brass ball $1 \cdot 25$ inches in diameter, and making it inducteously positive by an inductric negative point, the phenomena, at high degrees of rarefaction, were exceedingly beautiful. The glow came over the positive ball, and gradually increased in brightness, until it was at last very luminous; and it also stood up like a low flame, half an inch or more in height. On touching the sides of the glass jar this lainbent flame was affected, assumed a ring form, like a crown on the top of the ball, appeared flexible, and revolved with a comparatively slow motion, i. e. about four or five times in a second. This ringshape and revolution are beautifully connected with the mechanical currents (1576.) taking place within the receiver. These glows in rarefied air are often highly exalted in beauty by a spark discharge at the conductor (1551. Note).

1530. To obtain a negative glow in air' at common pressures is difficult. I did not procure it on the rod 0.3 of an inch in diameter by my machine, nor on much smaller rods; and it is questionable as yet, whether, even on fine points, what is called the negative star is a very reduced and ninute, but still intermitting brush, or a glow similar to that obtained on a positive point.

1531. In rarefied air the negative glow can easily be obtained. If the rounded ends of two metal rods, about 0.2 of an inch in diameter, are introduced into a globe or jar (the air within being rarefied), and being opposite to each other, are about four inches apart, the glow can be obtained on both rods, covering not only the ends, but an inch or two of the part behind. On using balls in the air-pump jar', and adjusting the distance and exhaustion, the negative ball could be covered with glow, whether it were the inductric or the inducteous surface.

1532. When rods are used it is necessary to be aware that, if placed concentrically in the jar or globe, the light on one rod is often reflected by the sides of the vessel on to the other rod, and makes it apparently luminous, when really it is not so. This 
effect may be detected by shifting the eye at the time of observation, or avoided by using blackened rods.

1533. It is curious to observe the relation of glow, brush, and spark to each other, as produced by positive or negative surfaces; thus, beginning with spark discharge, it passes into brush much sooner when the surface at which the discharge conmences (1484.) is negative, than it does when positive; but proceeding onwards in the order of change, we find that the positive brush passes into glow long before the negative brush does. So that, though each presents the three conditions in the same general order, the series are not precisely the same. It is probable, that, when these points are minutely examined, as they must be shortly, we shall find that each different gas or dielectric presents its own peculiar results, dependent upon the mode in which its particles assume polar electric condition.

1534. The glow occurs in all gases in which $I$ have looked for it. These are air, nitrogen, oxygen, hydrogen, coal gas, carbonic acid, muriatic acid, sulphurous acid and ammonia. I thought also that I obtained it in oil of turpentine, but if so it was very dull and small.

1535. The glow is always accompanied by a wind proceeding either directly out from the glowing part, or directly towards it; the former being the most general case. This takes place even when the glow occurs upon a ball of considerable size: and if matters be so arranged that the ready and regular access of air to a part exhibiting the glow be interfered with or prevented, the glow then disappears.

1536. I have never been able to analyse or separate the glow into visible elementary intermitting discharges (1427. 1433.), nor to obtain the other evidence of intermitting action, namely an audible sound (1431.). The want of success, as respects trials made by ocular means, may depend upon the large size of the glow preventing' the separation of the visible images : and, indeed, if it does intermit, it is not likely that all parts intermit at once with a simultaneous regularity.

1537. All the effects tend to show, that glow is due to a continuous charge or discharge of air; in the former case being accompanied by a current from, and in the latter by one to, the place of the glow. As the surrounding air comes up to the charged conductor, on attaining that spot at which the tension of the particles is raised to the sufficient degree (1370. 1410.), it becomes charged, and then moves off, by the joint action of the forces to which it is subject; and, at the same time that it makes way for other particles to come and be charged in turn, actually helps to form that current by which they are brought into the necessary position. 'Thus, through the regularity of the forces, a constant and quiet result is produced; and that result is, the charging of successive portions of air, the production of a current, and of a continuous glow.

1538. I have frequently been able to make the termination of a rod, which, when left to itself, would produce a brush, produce in preference a glow, simply by aiding the formation of a current of air at its extremity; and, on the other hand, it is not at all 
difficult to convert the glow into brushes, by affecting the current of air (1574.1579.) or the inductive action near it.

1539. The transition from glow, on the one hand, to brush and spark, on the other, and, therefore, their connexion, may be established in various ways. Those circumstances which tend to facilitate the charge of the air by the excited conductor, and also those which tend to keep the tension at the same degree notwithstanding the discharge, assist in producing the glow; whereas those which tend to resist the charge of the air or other dielectric, and those which favour the accumulation of electric force prior to discharge, which, sinking by that act, has to be exalted before the tension can again acquire the requisite degree, favour intermitting discharge, and, therefore, the production of brush or spark. Thus, rarefaction of the air, the removal of large conducting surfaces from the neighbourhood of the glowing termination, the presentation of a sharp point towards it, help to sustain or produce the glow: but the condensation of the air, the presentation of the hand or other large surface, the gradual approximation of a discharging ball, tend to convert the glow into brush or even spark. All these circumstances may be traced and reduced, in a manner easily comprehensible, to their relative power of assisting to produce, either a continuous discharge to the air, which gives the glow; or an interrupted one, which produces the brush, and, in a more exalted condition, the spark.

1540. The rounded end of a brass rod, 0.3 of an inch in diameter, was covered with a positive glow by the working of an electrical machine: on stopping the machine, so that the charge of the connected conductor should fall, the glow changed for a moinent into brushes just before the discharge ceased altogether, illustrating the necessity for a certain high continuous charge, for a certain sized termination. Working the machine so that the intensity should be just low enough to give continual brushes from the end in free air, the approach of a fine point changed these brushes into a glow. Working the machine so that the termination presented a continual glow in free air, the gradual approach of the hand caused the glow to contract at the very end of the wire, then to throw out a luminous point, which, becoming a foot stalk (1426.), finally produced brushes with large ramifications.

1541. Greasing the end of a rounded wire will immediately make it produce brushes instead of glow. A ball having a blunt point which can be made to project more or less beyond its surface, at pleasure, can be made to produce every gradation from glow, through brush, to spark.

1542. It is also very interesting and instructive to trace the transition from spark to glow, through the intermediate condition of stream, between ends in a vessel containing air more or less rarefied; but I fear to be prolix.

1543. All the effects show, that the glow is in its nature exactly the same as the luminous part of a brush or ramification, namely a charging of air ; the only difference being, that the glow has a continuous appearance from the constant renewal of 
the same action in the same place, whereas the ramification is due to a momentary, independent and intermitting action of the same kind.

\section{Dark Discharge.}

1544. I will now notice a very remarkable circumstance in the luminous discharge accompanied by negative glow, which may, perhaps, be correctly traced hereafter into discharges of much higher intensity. Two brass rods, 0.3 of an inch in diameter, entering a glass globe on opposite sides, had their ends brought into contact, and the air about them very much rarefied. A discharge of electricity from the machine was then made through them, and whilst that was continued the ends were separated from each other. At the moment of separation a continuous glow came over the end of the negative rod, the positive termination remaining quite dark. As the distance was increased, a purple stream or haze appeared on the end of the positive rod, and proceeded directly outwards towards the negative rod; elongating as the interval was enlarged, but never joining the negative glow, there being always a short dark space between. This space, of about $\frac{1}{16}$ th or $\frac{1}{2} \frac{1}{6}$ th of an inch, was apparently invariable in its extent and its position, relative to the negative rod; nor did the negative glow vary. Whether the negative end were inductric or inducteous, the same effect was produced. It was strange to see the positive purple haze diminish or lengthen as the ends were separated, and yet this dark space and the negative glow remain unaltered (fig. 19.).

1545. Two balls were then used in a large air pump receiver, and the air rarefied. The usual transitions in the character of the discharge took place; but whenever the luminous stream, which appears after the spark and the brush have ceased, was itself changed into glow at the balls, the dark space occurred, and that whether the one or the other ball was made inductric, or positive, or negative.

1546. Sometimes when the negative ball was large, the machine in powerful action, and the rarefaction high, the ball would be covered over half its surface with glow, and then, upon a hasty observation, would seem to exhibit no dark space: but this was a deception, arising from the overlapping of the convex termination of the negative glow and the concave termination of the positive stream. More careful observation and experiment have convinced me, that when the negative glow occurs it never visibly touches the luminous part of the positive discharge, but that the dark space is always there.

1547. This singular separation of the positive and negative discharge, as far as concerns their luminous character, under circunstances which one would have thought very favourable to their coalescence, is probably connected with their differences when in the form of brush, and is perhaps even dependent on the same 
cause. Further, there is every likelihood that the dark parts which occur in feeble sparks are also connected with these phenomena*. To understand them would be very important, for it is quite clear that in many of the experiments, indeed in all that I have quoted, discharge is taking place across the dark part of the dielectric to an extent quite equal to what occurs in the luminous part. This difference in the result would seem to imply a distinction in the modes by which the two electric forces are brought into equilibrium in the respective parts; and looking upon all the phenomena as giving additional proofs, that it is to the condition of the particles of the dielectric we must refer for the principles of induction and discharge, so it would be of great importance if we could know accurately in what the difference of action in the dark and the luminous parts consisted.

1548. The dark discharge through air (1552.), which in the case mentioned is very evident (1544.), leads to the inquiry, whether the particles of air are generally capable of effecting discharge from one to another without becoming luminous; and the inquiry is important, because it is connected with that degree of tension which is necessary to originate discharge (1368. 1370.). Discharge between air and conductors without luminous appearances are very common; and non-luminous discharges by carrying currents of air and other fluids $(1562.1595$.) are also common enough: but these are not cases in point, for they are not discharges between insulating particles.

1549. An arrangement was made for discharge between two balls (1485.) fig. 15., but, in place of connecting the inducteous ball directly with the discharging train, it was put in communication with the inside coating of a Leyden jar, and the discharging train with the outside coating. Then working the machine, it was found that whenever sonorous and luminous discharge occurred at the balls $A B$, the jar became charged; but that when these did not occur, the jar acquired no charge: and such was the case when small rounded terminations were used in place of the balls, and also in whatever manner they were arranged. Under these circumstances, therefore, discharge even between the air and conductors was always luminous.

1550. But in other cases, the phenomena are such as to make it almost certain, that dark discharge can take place across air. If the rounded end of a metal rod, 0.15 of an inch in diameter, be made to give a good negative brush, the approach of a smaller end or a blunt point opposite to it will, at a certain distance, cause a diminution of the brush, and a glow will appear on the positive inducteous wire, accompanied by a current of air passing from it. Now, as the air is being charged both at the positive and negative surfaces, it seems a reasonable conclusion, that the charged portions meet somewhere in the interval, and there discharge to each other, without producing any luminous phenomena. It is possible, however, that the air electrified positively at the glowing end may travel on towards the negative surface, and actually form that atmosphere into which the visible negative brushes dart, in which case

* See Professor Johnson's experiments. Sinliman's Journal, xxv. p. 57. 
dark discharge need not, of necessity, occur. But I incline to the former opinion, and think; that the diminution in size of the negative brush, as the positive glow comes on to the end of the opposed wire, is in favour of that view.

1551. Using rarefied air as the dielectric, it is very easy to obtain luminous phenomena as brushes, or glow, upon both conducting balls or terminations, whilst the interval is dark, and that, when the action is so momentary that $I$ think we cannot refer to currents as affecting discharge across the dark part. Thus if two balls, about an inch in diameter, and 4 or more inches apart, have the air rarefied about them, and are then interposed in the course of discharge, an interrupted or spark current being produced at the machine*, each termination may be made to show luminous phenomena, whilst more or less of the interval is quite dark. The discharge will pass as suddenly as a retarded spark (295.334.), i. e. in an interval of time almost inappreciably small, and in such a case, I think it must have passed across the dark part as true disruptive discharge, and not by convection.

1552. Hence I conclude that dark disruptive discharge may occur (1547. 1550.); and also, that, in the luminous brush, the visible ramifications may not show the full extent of the disruptive discharge (1444. 1452.), but that each may have a dark outside, enveloping, as it were, every part through which the discharge extends. It is probable, even, that there are such things as dark discharges analogous in form to the brush and the spark, but not luminous in any part (1445.).

1553. The occurrence of dark discharge in any case shows at how low a tension disruptive discharge may occur (1548.), and indicates that the light of the ultimate brush or spark is in no relation to the intensity required (1368. 1370.). So to speak, the discharge begins in darkness, and the light is a mere consequence of the quantity which, after discharge has cominenced, flows to that spot and there finds its most facile passage (1418. 1435.). As an illustration of the growth generally of discharge, I may remark that, in the experiments on the transition in oxygen of the discharge from spark to brush (1518.), every spark was immediately preceded by a short brush.

1554. The phenomena relative to dark discharge in other gases, though differing in certain characters from those in air, confirm the conclusions drawn above. The two rounded terminations (1544.) (fig. 19.), were placed in muriatic acid gas (1445. 1463.) at the pressure of 6.5 inches of mercury, and a continuous machine current of electricity sent through the apparatus : bright sparks occurred until the interval was about or above an inch, when they were replaced by squat brushy intermitting glows upon both terminations, with a dark part between. When the current at the machine was in spark, then each spark caused a discharge across the muriatic acid gas, which, with a certain interval, was bright ; with a larger interval, was straight across

* By spark current I mean one passing in a series of spark between the conductor of the machine and the apparatus : by a continuous current one that passes through metallic conductors, and in that respect without interruption at the same place. 
and flamy, like a very exhausted and sudden, but not a dense sharp spark; and with a still larger interval, produced a feeble brush on the inductric positive end, and a glow on the inducteous negative end, the dark part being between (1544.); and at such times, the spark at the conductor, instead of being sudden and sonorous, was dull and quiet (334.).

1555. On introducing more muriatic acid gas, until the pressure was 29.97 inches, the same terminations gave bright sparks within at small distances; but when they were about an inch or more apart, the discharge was generally with very small brushes and glow, and frequently with no light at all, though electricity had passed through the gas. Whenever the bright spark did pass through the muriatic acid gas at this pressure, it was bright throughout, presenting no dark or dull space.

1556. In coal gas, at common pressures, when the distance was about an inch, the discharge was accompanied by short brushes on the ends, and a dark interval of half an inch or more between them, notwithstanding the discharge had the sharp quick sound of a dull spark, and could not have depended in the dark part on convection.

1557. This gas presents several curious points in relation to the bright and dark parts of spark discharge. When bright sparks passed between the rod ends 0.3 of an inch in diameter (1544.), very sudden dark parts would occur next to the brightest portions of the spark. Again, with these ends and also with balls (1422.), the bright sparks would be sometimes red, sometimes green, and occasionally green and red in different parts of the same spark. Again, in the experiments described (1518.), at certain intervals a very peculiar pale, dull, yet sudden discharge would pass, which, though apparently weak, was very direct in its course, and accompanied by a sharp snapping noise, as if quick in its occurrence.

1558. Hydrogen frequently gave peculiar sparks, one part being bright red, whilst the other was a dull pale gray, or else the whole spark was dull and peculiar.

1559. Nitrogen presented a very remarkable discharge, between two balls of the respective diameters of $0 \cdot 15$ and 2 inches (1506. 1518.), the smaller one being rendered negative either directly or inducteously. The peculiar discharge occurred at intervals between $0 \cdot 42$ and $0 \cdot 68$, and even at $1 \cdot 4$ inches when the large ball was inductric positively; it consisted of a little brushy part on the small negative ball, then a dark space, and lastly a dull straight line on the large positive ball (fig. 20.). The position of the dark space was very constant, and is probably in direct relation to the dark space described when negative glow was produced (1544.). When by any circumstance a bright spark was determined, the contrast with the peculiar spark described was very striking; for it always had a faint purple part, but the place of this part was constantly near the positive ball.

1560. Thus dark discharge appears to be decidedly established. But its establishment is accompanied by proofs that it occurs in different degrees and modes in different gases. Hence then another specific action, added to the many (1296. 1398. 1399. 1423. 1454.1503.) by which the electrical relations of insulating dielectrics are distin- 
guished and established, and another argument in favour of that molecular theory of induction, which is at present under examination*.

1561. What I have had to say regarding the disruptive discharge has extended to some length, but I hope will be excused in consequence of the importance of the subject. Before concluding my remarks, I will again intimate in the form of a query, whether we have not reason to consider the tension or retention and after discharge in air or other insulating dielectrics, as the same thing with retardation and discharge in a metal wire, differing only, but almost infinitely, in degree (1334. 1336.). In other words, can we not, by a gradual chain of association, carry up discharge from its occurrence in air, through spermaceti and water, to solutions, and then on to chlorides, oxides and metals, without any essential change in its character ; and at the same time, connecting the insensible conduction of air, through muriatic acid gas and the dark discharge, with the better conduction of spermaceti, water, and the all but perfect conduction of the metals, associate the phenomena at both extremes? and may it not be, that the retardation and ignition of a wire are effects exactly correspondent in their nature to the retention of charge and spark in air? If so, here again the two extremes in property amongst dielectrics will be found to be in intimate relation, the whole difference probably depending upon the mode and degree in which their particles polarize under the influence of inductive actions (1338. 1603. 1610.).

\section{T $\mathrm{x}$. Convection; or carrying discharge.}

1562. The last kind of discharge which $I$ have to consider is that effected by the motion of charged particles from place to place. It is apparently very different in its nature to any of the former modes of discharge (1319.), but, as the result is the same, may be of great importance in illustrating, not merely the nature of discharge itself, but also of what we call the electric current. It often, as before observed, in cases of brush and glow (1440.1535.), joins its effect to that of disruptive discharge, to complete the act of neutralization amongst the electric forces.

1563. The particles which being charged, then travel, may be either of insulating or conducting matter, large or small. The consideration in the first place of a large particle of conducting matter may perhaps help our conceptions.

1564. A copper boiler 3 feet in diameter was insulated and electrified, but so feebly, that dissipation by brushes or disruptive discharge did not occur at its edges or projecting parts in a sensible degree. A brass ball, 2 inches in diameter, suspended by

* I cannot resist referring here by a note to Broт's philosophical view of the nature of the light of the electric discharge, Annales de Chimie, liii. p. 321. 
a clean white silk thread, was brought towards it, and it was found that, if the ball was held for a second or two near any part of the charged surface of the boiler, at such distance (two inches more or less) as not to receive any direct charge from it, it became itself charged, although insulated the whole time; and its electricity was the reverse of that of the boiler.

1565. This effect was the strongest opposite the edges and projecting parts of the boiler, and weaker opposite the sides, or those extended portions of the surface which, according to Couloms's results, have the weakest charge. It was very strong opposite a rod projecting a little way from the boiler. It occurred when the copper was charged negatively as well as positively : it was produced also with small balls down to 0.2 of an inch and less in diameter, and also with smaller charged conductors than the copper. It is, indeed, hardly possible in some cases to carry an insulated ball within an inch or two of a charged plane or convex surface without its receiving a charge of the contrary kind to that of the surface.

1566. This effect is one of induction, not of communication. The ball, when related to the positive charged surface by the intervening dielectric, has its opposite sides brought into contrary.states, that side towards the boiler being negative and the outer side positive. More inductric action is directed towards it than would have passed across the same place if the ball had not been there, for several reasons; amongst other's, because, being a conductor, the resistance of the particles of the dielectric, which otherwise would have been there, is removed (1298.); and also, because the reacting positive surface of the ball being projected further out from the boiler than when there is no introduction of conducting matter, is more free therefore to act through the rest of the dielectric towards surrounding conductors, and so favours the exaltation of that inductric polarity which is directed in its course. It is, as to the exaltation of force upon its outer surface beyond that upon the inductric surface of the boiler, as if the latter were itself protuberant in that direction. Thus it acquires a state like, but higher than, that of the surface of the boiler which causes it ; and sufficiently exalted to discharge at its positive surface to the air, or to affect small particles, as it is itself affected by the boiler, and they flying to it, take a charge and pass off; and so the ball, as a whole, is brought into the contrary inducteous state. The consequence is, that, if free to move, its tendency, under the influence of all the forces, to approach the boiler is increased, whilst it at the same time becomes more and more exalted in its condition, both of polarity and charge, until, at a certain distance, discharge takes place, it acquires the same state as the boiler, is repelled, and passing to that conductor most favourably circumstanced to discharge it, there resumes its first indifferent condition.

1567. It seems to me, that the manner in which inductric bodies affect uncharged floating or moveable conductors near them, is very frequently of this nature, and generally so when it ends in a carrying operation (1562. 1602.). The manner in which, whilst the dominant inductric body cannot give off its electricity to the air, the in- 
ducteous body can effect the discharge of the same kind of force, is curious, and, in the case of elongated or irregularly shaped conductors, such as filaments or particles of dust, the effect will often be very ready, and the consequent attraction very immediate.

1568. The effect described is also probably influential in causing those variations in spark discharge referred to in the last series (1386. 1390.) : for if a particle of dust were drawn towards the axis of induction between the balls, it would tend, whilst at some distance from that axis, to commence discharge at itself, in the manner described (1566.), and that commencement might so far facilitate the act (1417. 1420.) as to make the complete discharge, as spark, pass through the particle, though it might not be the shortest course from ball to ball. So also, with equal balls at equal distances, as in the experiments of comparison already described (1493. 1506.), a particle being between one pair of balls would cause discharge there in preference; or even if a particle were between each, difference of size or shape would give one for the time a predominance over the other.

1569. The power of particles of dust to carry off electricity in cases of high tension is well known, and I have already mentioned some instances of the kind in the use of the inductive apparatus (1201.). The general operation is very well shown by large light objects, as the toy called the electrical spider ; or, if smaller ones are wanted for philosophical investigation, by the smoke of a glowing green wax taper, which, presenting a successive stream of such particles, makes their course visible.

1570. On using oil of turpentine as the dielectric, the action and course of small conducting carrying particles in it can be well observed. A few short pieces of thread will supply the place of carriers, and their progressive action is exceedingly interesting.

1571. A very striking effect was produced on oil of turpentine, which, whether it was due to the carrying power of the particles in it, or to any other action of them, is perhaps as yet doubtful. A portion of that fluid in a glass vessel had a large uninsulated silver dish at the bottom, and an electrified metal rod with a round termination dipping into it at the top. The insulation was very good, and the attraction and other phenomena striking. The rod end, with a drop of gum water attached to it, was then electrified in the fluid; the gum water soon spun off in fine threads, and was quickly dissipated through the oil of turpentine. By the time that four drops had in this way been commingled with a pint of the dielectric, the latter had lost by far the greatest portion of its insulating power; no sparks could be obtained in the fluid; and all the phenomena dependent upon insulation had sunk to a low degree. The fluid was very slightly turbid. Upon being filtered through paper only, it resumed its first clearness, and now insulated as well as before. The water, therefore, was merely diffused through the oil of turpentine, not combined with or dissolved in it: but whether the minute particles acted as carriers, or whether they were not rather gathered together in the line of highest inductive tension (1350.), and there, 
being drawn into elongated forms by the electric forces, combined their effects to produce a band of matter having considerable conducting power, as compared with the oil of turpentine elsewhere, is as yet questionable.

1572. The analogy between the action of solid conducting carrying particles and that of the charged particles of fluid insulating substances, acting as dielectrics, is very evident and simple; but in the latter case the result is, necessarily, currents in the mobile media. Particles are brought by inductric action into a polar state; and the latter, after rising to a certain tension (1370.), is followed by the communication of a part of the force originally on the conductor; the particles consequently become charged, and then, under the joint influence of the repellent and attractive forces, are urged towards a discharging place, or to that spot where these inductric forces are most easily compensated by the contrary inducteous forces.

1573. Why a point should be so exceedingly favourable to the production of currents in a fluid insulating dielectric, as air, is very evident. It is at the extremity of the point that the intensity necessary to charge the air is first acquired (1374.); it is from thence that the charged particle recedes; and the mechanical force which it inpresses on the air to form a current, is in every way favoured by the shape and position of the rod, of which the point forms the termination. At the same time, the point, having become the origin of an active mechanical force, does, by the very act of causing that force, namely, by discharge, prevent any other part of the rod from acquiring the same necessary condition, and so preserves and sustains its own predominance.

1574. The very varied and beautiful phenomena produced by sheltering or enclosing the point, illustrate the production of the current exceedingly well, and justify the same conclusions; it being remembered that in such cases the effect upon the discharge is of two kinds. For the current may be interfered with by stopping the access of fresh uncharged air, or retarding the removal of that which has been charged, as when a point is electrified in a tube of insulating matter closed at one extremity; or the electric condition of the point itself may be altered by the relation of other parts in its neighbourhood, also rendered electric, as when the point is in a metal tube, by the metal itself, or when it is in the glass tube, by a similar action of the charged parts of the glass, or even by the surrounding air which has been charged, and which cannot escape.

1575. Whenever it is intended to observe such inductive phenomena in a fluid dielectric as have a direct relation to, and dependence upon, the fluidity of the medium, such, for instance, as a discharge from points, or attractions and repulsions, \&c., then the mass of the fluid should be great, and in such proportion to the distance between the inductric and inducteous surfaces as to include all the lines of inductive force (1369.) between them; otherwise, the effects of currents, attraction, \&c., which are the resultants of all these forces, cannot be obtained. The phenomena which occur in the open air, or in the middle of a globe filled with oil of turpentine, will not take place MDCCCXXXvill. 
in the same media if confined in tubes of glass, shell-lac, sulphur, or other such substances, though they be excellent insulating dielectrics; nor can they be expected; for in such cases, the polar forces, instead of being all dispersed amongst fluid particles, which tend to move under their influence, are now associated in many parts with particles that, notwithstanding their tendency to inotion, are constrained to remain quiescent.

1576. The varied circumstances under which, with condnctors differently forned and constituted, currents can occur, all illustrate the same simplicity of production. A ball, if the intensity be raised sufficiently on its surface, and that intensity be greatest on a part consistent with the production of a current of air up to and off from it, will produce the effect like a point (1537.); such is the case whenever the glow occurs upon a ball, the current being essential to that phenomenon. If as large a sphere as can well be employed with the production of glow be used, the glow will appear at the place where the current leaves the ball, and that will be the part directly opposite to the connection of the ball and rod which supports it ; but by increasing the tension elsewhere, so as to raise it above the tension upon that spot, which can easily be effected inductively, then the place of the glow and the direction of the current will also change, and pass to that spot which for the time is most favourable for their production (1591.).

1577. For instance, approaching the hand towards the ball will tend to cause brush (1539.), but by increasing the supply of electricity the condition of glow may be preserved; then on moving the hand about from side to side the position of the glow will very evidently move with it.

157. A point brought towards a glowing ball would at twelve or fourteen inches distance nake the glow break into brush, but when still nearer glow was reproduced, probably dependent upon the discharge of wind or air passing from the point to the ball, and this glow was very obedient to the motion of the point, following it in every direction.

1579. Even a current of wind could affect the place of the glow; for a varnished glass tube being directed sideways towards the ball, air was sometimes blown through it at the ball, and sometimes not. In the former case, the place of the glow was changed a little, as if it were blown away by the current, and this is just the result which might have been anticipated. All these effects illustrate beautifully the general causes and relations, both of the glow and the current of air accompanying it (1574).

1580. Flame facilitates the production of a current in the dielectric surrounding it. Thus, if a ball which would not occasion a current in the air have a flame, whether large or small, formed on its surface, the current is produced with the greatest ease; but not the least difficulty can occur in comprehending the effective action of the flame in this case, if its relation, as part of the surrounding dielectric, to the electrified ball, be but for a moment considered (1375. 1380.). 
1581. Conducting fluid terminations, instead of rigid points, illustrate in a very beautiful manner the formation of the currents, with their effects and influence in exalting the conditions under which they were commenced. Let the rounded cnd of a brass rod, 0.3 of an inch or thereabouts in diameter, point downwards in free air; let it be amalgamated, and have a drop of mercury suspended from it; and then let it be powerfully electrized. The mercury, will present the phenomenon of glow; a current of air will rush along the rod, and set off from the mercury directly downwards; and the form of the metallic drop will be slightly affected, the convexity at a small part near the middle and lower part becoming greater, whilst it diminishes all round at places a little removed from this spot. The change is from the form of $a$ (fig. 21.) to that of $b$, and is due almost, if not entirely, to the mechanical force of the current of air sweeping over its surface.

1582. As a comparative observation, let it be noticed, that a ball gradually brought towards it converts the glow into brushes, and ultimately sparks pass from the most projecting part of the mercury. A point does the same, but at much smaller distances.

1583. Take next a drop of strong solution of muriate of line; being electrified, a part will probably. be dissipated, but a considerable portion, if the electricity be not too powerful, will remain, forming a conical drop (fig. 22.), accompanied by a strong current. If glow be produced, the diop will be smooth on the surface. If a short low brush is formed, a minute tremulous motion of the liquid will be visible; but both effects coincide with the principal one to be observed, namely, the regular and continuous charge of air, the formation of a wind or current, and the form given by that current to the fluid drop. If a discharge ball be gradually brought toward the cone, sparks will at last pass, and these will be from the apex of the cone to the approached ball, indicating a considerable degree of conducting power in this fluid.

1584. With a drop of water, the effects were of the same kind, and were best obtained when a portion of gum water or of syrup hung from a ball (fig. 23.). When the machine was worked slowly, a fine large quiet conical drop, with concave lateral outline, and a small rounded end, was produced, on which the glow appeared, whilst a steady wind issued, in a direction from the point of the cone, of sufficient force to depress the surface of uninsulated water held opposite to the termination. When the machine was worked more rapidly some of the water was driven off; the smaller pointed portion left was roughish on the surface, and the sound of successive brush discharges was heard. With still more electricity, more water was dispersed; that which remained was elongated and contracted, with an alternating motion; a stronger brush discharge was heard, and the vibrations of the water and the successive discharges of the individual brushes were simultaneous. When water from beneath was brought towards the drop, it did not indicate the same regular strong contracted current of air as before; and when the distance was such that sparks passed, 
the water beneath was attracted rather than driven away, and the current of air ceased.

1585. When the discharging ball was brought near the drop in its first quiet glowing state (1582.), it converted that glow into brushes, and caused the vibrating motion of the drop. When still nearer, sparks passed, but they were always from the metal of the rod, over the surface of the water, to the point, and then across the air to the ball. 'This is a natural consequence of the deficient conducting power of the fluid (1584. 1585.).

1586. Why the drop vibrated, changing its form between the periods of discharging brushes, so as to be more or less acute at particular instants, to be most acute when the brush issued forth, and to be isochronous in its action, and how the quiet glowing liquid drop, on assuming the conical form, facilitated, as it were, the first action, are points, as to theory, so evident, that I will not stop to speak of them. The principal thing to obscrve at present is, the formation of the carrying current of air, and the manner in which it exhibits its existence and influence by giving form to the drop.

1587. That the drop, when of water, or a better conductor than water, is formed into a cone principally by the current of air, is shown anongst other ways (1594.) thus. A sharp point being held opposite the conical drop, the latter soon lost its pointed form; was retracted and became round; the current of air from it ceased, and was replaced by one from the point beneath, which, if the latter were held near enough to the drop, actually blew it aside, and rendered it concave in form.

1588. It is hardly necessary to say what happened with still worse conductors than water, as oil, or oil of turpentine; the fluid itself was then spun out into threads and carried off, not only because the air rushing over its surface, helped to sweep it away, but also because its insulating particles assumed the same charged state as the particlcs of air, and, not being able to discharge to them in a greater degree than the air particles themselves could do, were carried off by the same causes which urged these in their course. A similar effect with melted sealing-wax on a metal point forms an old and well-known experiment.

1589. A drop of gum water in the exhausted receiver of the air-pump was not sensibly affected in its form when electrified. When air was let in, it began to show. change of shape when the pressure was ten inches of mercury. At the pressure of fourteen or fiftcen inches the change was more sensible, and as the air increased in density the effects increased, until they were the same as those in the open atmosphere. The diminished effect in the rare air I refer to the relative diminished energy of its current; that diminution depending, in the first place, on the lower electric condition of the electrified ball in the rarefied nedium, and in the next, on the attenuated condition of the dielectric, the cohesive force of water in relation to rarefied air being something like that of mercury to dense air (1581.), whilst that of water in dense air may be compared to that of mercury in oil of turpentine (1597.). 
1590. When a ball is covered with a thick conducting fluid, as treacle or syrup, it is easy by inductive action to detcrmine the wind from almost any part of it (1577.); the experiment, which before was of rather difficult performancc, being rendered facile in consequence of the fluid enabling that part, which at first was feeblc in its action, to rise into an exalted condition by assuming a pointed form.

1591. To produce the current, the electric intensity must rise and continue at one spot, namely, at the origin of the current, higher than elsewhere, and then, air having a uniform and ready access, the current is produced. If no current be allowed (1574.), then discharge may take place by brush or spark. But whether it be by brush or spark, or wind, it seems very probablc that the initial intensity or tcnsion at which a particle of a given gaseous diclectric charges, or commences discharge, is, under the conditions before expressed, always the same (1410.).

1592. It is not supposed that all the air which enters into motion is clectrified; on the contrary, much that is not charged is carried on into the stream. The part which is really charged may be but a small proportion of that which is ultimately set in motion (1442.).

1593. When a drop of gum water (1584.) is made negative, it presents a larger cone than when made positive; less of the fluid is thrown off, and yet, when a ball is approached, sparks can hardly be obtained, so pointed is the cone, and so free the discharge. A point held opposite to it did not cause the retraction of the cone to such an extent as when it was positive. All the effects are so different from those presented by the positive cone, that I have no doubt such drops would present a very instructive method of investigating the difference of positive and negative discharge in air and other dielectrics (1480. 1501.).

1594. That I may not be misunderstood (1587.), I must observe here that I do not consider the cones produced as the result only of the current of air or other insulating dielectric over their surface. When the drop is of badly conducting matter, a part of the effect is due to the electrified state of the particles, and this part constitutes almost the whole when the matter is sealing-wax, oil of turpentine, and similar insulating bodies (1588.). But even when the drop is of good conducting matter, as water, solutions, or mercury, though the effect above spoken of will then be insensible 1607.), still it is not the mere current of air or other dielectric which produces all the change of form; for a part is due to those attractive forces by which the charged clrop, if free to move, would travel along the line of strongest induction, and not being free to move, has its form elongated until the sum of the different forces tending to produce this form is balanced by the cohesive attraction of the fluid. The effect of the attractive forces are well shown when treacle, gum water, or syrup is used; for the long threads which spin out, at the same time that they form the axes of the currents of air, which may still be considered as determined at their points, are like flexible conductors, and show by their directions in what way the attractive forces draw them. 
1595. When the phenomena of currents are observed in dense insulating dielectrics, they present us with extraordinary degrees of mechanical force. Thus, if a pint of well rectified and filtered (1571.) oil of turpentine be put into a glass vessel, and two wires be dipped into it in different places, one leading to the electrical machine, and the other to the discharging train, on working the machine the fluid will be thrown into violent inotion throughout its whole mass, whilst at the same time it will rise two, three, or four inches up the machine wire, and dart off in jets from it into the air.

1596. If very clean uninsulated inercury be at the bottom of the fluid, and the wire from the machine be terminated either by a ball or a point, and also pass through a glass tube extending both above and below the surface of the oil of turpentine, the currents can be better observed, and will be seen to rush down the wire, proceeding directly from it towards the mercury, and there, diverging in all directions, will ripple its surface strongly, and mounting up at the sides of the vessel, will return to re-enter upon their course.

1597. A drop of mercury being suspended from an amalgamated brass ball, preserved its form almost unchanged in air (1581.); but when immersed in the oil of turpentine it became very pointed, and even particles of the metal could be spun out and carried off by the currents of the dielectric. The form of the liquid metal was just like that of the syrup in air (1584.), the point of the cone being quite as fine, though not so long. By bringing a sharp uninsulated point towards it, it could also be effected in the same manner as the syrup drop in air (1587.), though not so readily, because of the density and limited quantity of the dielectric.

3598. If the mercury at the bottom of the fluid be connected with the electrical machine, whilst a rod is held in the hand terminating in a ball three quarters of an inch, less or more, in diameter, and the ball be dipped into the electrified fluid, very striking appearances ensue. When the ball is raised again so as to be at a level nearly out of the fluid, large portions of the latter will seem to cling to it (fig. 24.). If it be raised higher, a column of the oil of turpentine will still connect it with that in the basin below (fig. 25.). If the machine be excited into more powerful action, this will become more bulky, and may then also be raised higher, assuming the form fig. 26 ; and all the time that these effects continue, currents and counter-currents, sometimes running very close together, may be observed in the raised column of fluid.

1599. It is very difficult to decide by sight the direction of the currents in such experiments as these. If particles of silk are introduced they cling about the conductors ; but using drops of water and mercury the course of the fluid dielectric seems well indicated. Thus, if a drop of water be placed at the end of a rod (1571.) over the uninsulated mercury, it is soon swept away in particles streaming downwards towards the mercury. If another drop be placed on the mercury beneath the end of the rod, it is quickly dispersed in all directions in the form of streaming particles, the attractive forces drawing it into elongated portions, and the currents carrying thein away 
If a drop of mercury be hung from a ball used to raise a column of the fluid (1598.), then the shape of the drop seems to show currents travelling in the fluid in the direction indicated by the arrows (fig. 27.).

1600. A very remarkable effect is produced on these phenomena, connected with positive and negative charge and discharge, namely, that a ball charged positively raises a much higher and larger column of the oil of turpentine than when charged negatively. There can be no doubt that this is connected with the difference of positive and negative action already spoken of (1480.1525.), and tends much to strengthen the idea that such difference is referable to the particles of the dielectric rather than to the charged conductors, and is dependent upon the mode in which these particles polarize (1503. 1523.).

1601. Whenever currents travel in insulating dielectrics they really effect discharge; and it is important to observe, though a very natural result, that it is indifferent which way the current or particles travel, as with reversed direction their state is reversed. The change is easily made, either in air or oil of turpentine, between two opposed and related rods, for an insulated ball being placed in connexion with either rod and brought near its extremity, will cause the current to set towards it from the opposite end.

1602. The two currents often occur at once, as when both terminations present brushes, and frequently when they exhibit the glow (1531.). In such cases, the charged particles, or many of them, meet and mutually discharge each other (1548. 1612.). If a smoking wax taper be held at the end of an insulating rod towards a charged prime conductor, it will very often happen that two currents will form, and be rendered visible by its vapour, one passing as a fine filament of smoky particles directly to the charged conductor, and the other passing as directly from the same taper wick outwards, and from the conductor; the principles of inductric action and charge, which were referred to in considering the relation of a carrier ball and a conductor (1566.), being here also called into play.

1603. The general analogy and, I think I may say, identity of action found to exist as to insulation and conduction (1338. 1561.) when bodies, the best and the worst in the classes of insulators or conductors, were compared, led me to believe that the phenomena of convection in badly conducting media were not without their parallel amongst the best conductors, such even as the metals. Upon consideration, the cones produced by DAvY* in fluid metals, as mercury and tin, seemed to be cases in point, and probably also the elongation of the metallic medium through which a current of electricity was passing, described by AMPERE $\uparrow$; for it is not difficult to conceive,

* Philosophical Transactions, 1823, p. 155.

† Bibliotheque Universelle, xxj. 47. 
that the diminution of convective effect, consequent upon the high conducting power of the metallic media used in these experiments, might be fully compensated for by the enormous quantity of electricity passing. In fact, it is impossible not to expect some effect, whether sensible or not, of the kind in question, when such a current is passing through a fluid offering a sensible resistance to the passage of the electricity, and, thereby, giving proof of a certain degree of insulating power (1328.).

1604. I endeavoured to connect the convective currents in air, oil of turpentine, \&c. and those in metals, by intermediate cases, but found this not easy to do. On taking bodies, for instance, which, like water, acids, solutions, fused salts or chlorides, \&c., have interinediate conducting powers, the minute quantity of electricity which the common ulachine can supply (371.861.) is exhausted instantly, so that the cause of the phenomenon is kept either very low in intensity, or the instant of time during which the effect lasts is so small, that one cannot hope to observe the result sought for. If a voltaic battery be used, these bodies are all electrolytes, and the evolution of gas, or the production of other changes, interferes and prevents observation of the effect required.

1605. There are, nevertheless, some experiments which illustrate the connection. Two platina wires, forming the electrodes of a powerful voltaic battery, were placed side by side, near each other, in distilled water, hermetically sealed up in a strong glass tube, some minute filaments being present in the water. When, from the evolution of gas and the consequent increased pressure, the bubbles formed on the electrodes were so small as to produce but feebly ascending currents, then it could be observed that the filaments present were attracted and repelled between the two wires, as they would have been between two oppositely charged surfaces in air or oil of turpentine, moving so quickly as to displace and disturb the bubbles and the currents which these tended to form. Now I think it cannot be doubted that under similar circunıstances, and with an abundant supply of electricity, of sufficient tension also, convective currents might have been formed; the attractions and repulsions of the filaments were, in fact, the elements of such currents (1572.), and therefore water, though almost infinitely above air or oil of turpentine as a conductor, is a medium in which similar currents can take place.

1606. I had an apparatus made (fig. 28.) in which $a$ is a plate of shell-lac, $b$ a fine platina wire passing through it, and having only the section of the wire exposed above; $c$ a ring of bibulous paper resting on the shell-lac, and $d$ distilled water retained by the paper in its place, and just sufficient in quantity to cover the end of the wire $b$; another wire, $e$, touched a piece of tin foil lying in the water, and was also connected with a discharging train; in this way it was easy, by rendering $b$ either positive or negative, to send a current of electricity by its extremity into the fluid, and so away by the wire $e$.

1607. On conrecting $b$ with the conductor of a powerful electrical machine, not the least disturbance of the level of the fluid over the end of the wire during the 
working of the machine could be observed; but at the same time there was not the smallest indication of electrical charge about the conductor of the machine, so complete was the discharge. I conclude that the quantity of electricity passed in a given time had been too small, when compared with the conducting power of the fluid, to produce the desired effect.

1608. I then charged a large Leyden battery (291.), and discharged it through the wire $b$, interposing, however, a wet thread, two feet long, to prevent a spark in the water, and to reduce what would else have been a sudden violent discharge into one of more moderate character, enduring for a sensible length of time (334.). I now did obtain a very brief elevation of the water over the end of the wire; and though a few minute bubbles of gas were at the same time formed there, so as to prevent me from asserting that the effect was unequivocally the same as that obtained by $D_{A v Y}$ in the metals, yet, according to my best judgement, it was partly, and I believe principally, of that nature.

1609. I employed a voltaic battery of 100 pair of four-inch plates for experiments of a similar nature with electrolytes. In these cases the shell-lac was cupped, and the wire $b 0.2$ of an inch in diameter. Sometimes I used a positive amalgamated zinc wire in contact with dilute sulphuric acid; at others, a negative copper wire in a solution of sulphate of copper; but, because of the evolution of gas, the precipitation of copper, \&c., I was not able to obtain decided results. It is but right to mention, that when I made use of mercury, endeavouring to repeat Davy's experiment, the battery of 100 pair was not sufficient to produce the elevations*.

1610. The latter experiments (1609.) may therefore be considered as failing to give the hoped-for proof, but I have much confidence in the former (1605. 1608.), and in the considerations (1603.) connected with them. If I have rightly viewed them, and we may be allowed to relate the currents at points and surfaces in such extremely different bodies as air and the metals, and admit that they are effects of the same kind, differing only in degree and in proportion to the insulating or conducting power of the dielectric used, what great additional argument we obtain in favour of that theory, which in the phenomena of insulation and conduction also, as in these, would link the same apparently dissimilar substances together (1336. 1561.); and how completely the general view, which refers all the phenomena to the direct action of the molecules of matter, seems to embrace the various isolated phenomena as they successively come under consideration!

1611. The connection of this convective or carrying effect, which depends upon a certain degree of insulation, with conduction; i. e. the occurrence of both in so many

* In the experiments at the Royal Institution, Sir H. DAVY used, I think, 500 or 600 pairs of plates. Those at the London Institution were made with the apparatus of Mr. PEPYs, (consisting of an enormous single pair of plates), described in the Philosophical Transactions for 1823, p. 187.

MDCCCXXXVIII. 
of the substances referred to, as, for instance, the metals, water, air, \&c., would lead to many very curious theoretical generalizations, which I must not indulge in here. One point, however, I shall venture to refer to. Conduction appears to be essentially an action of contiguous particles, and the considerations just stated, together with other's formerly expressed (1326. 1336, \&c.), lead to the conclusion, that all bodies conduct, and by the same process, air as well as metals; the only difference bcing in the necessary degree of force or tension between the particles which must exist before the act of conduction or transfer from one particle to another can take place.

1612. The question then arises, what is this limiting condition which separates, as it wcre, conduction and insulation from each other? Does it consist in a difference between the two contiguous particles, or the contiguous poles of these particles in the nature and amount of positive and negative force, no communication or discharge occurring unless that difference rises up to a certain degree, variable for different bodies, but always the same for the same body? Or is it true that, however small the difference between two such particles, if time be allowed, equalization of force will take place, even with the particles of such bodies as air, sulphur or lac? In the first case, insulating powcr in any particular body would be proportionate to the degree of the assumed nccessary difference of force; in the second, to the time required to equalize equal degrees of difference in different bodies. With regard to airs, one is almost led to expect a permancnt difference of force, but in all other bodies, time seems to be quite sufficient to ensure, ultimately, complete conduction. The difference in the modes by which insulation may be sustained, or conduction effected, is not a mere fanciful point, but one of great inportance, as being essentialiy connected with the molecular theory of induction, and the manner in which the particles of bodies assume and retain their polarized state.

\section{9 xi. Relation of a vacuum to electrical phenomena.}

1613. It would seem strange if a theory which refers all the phenomena of insulation and conduction, i. e. all electrical phenomena, to the action of contiguous particles, were to omit to notice the assumed possible case of a vacuum. Admitting that a vacuum can be produced, it would be a very curious matter indeed to know what its rclation to electrical phenomena would be ; and as shell-lac and metal are directly opposed to each other, whether a vacuum would be opposed to them both, and allow neither of induction or conduction across it. Mr. MongaN* has said that a vacuum does not conduct. Sir H. DAvY concluded from his investigations, that as perfect a vacuum as could be made $\gamma$ did conduct, but does not consider the prepared spaces which he used as absolute vacua. In such experiments I think I have observed the 
luminous discharge to be principally on the inner surface of the glass; and it does not appear at all unlikely, that, if the vacuum refused to conduct, still the surface of glass next it might carry on that action.

1614. At one time, when I thought inductive force was exerted in right lines, I hoped to illustrate this important question by making experiments on induction with metallic mirrors (used only as conducting vessels) exposed towards a very clear sky at night time, and of such concavity that nothing but the firmament could be visible from the lowest part of the concave $n$, fig. 29. Such mirrors, when electrified, as by connection with a Leyden jar, and examined by a carrier ball, readily gave electricity at the lowest part of their concavity if in a room ; but I was in hopes of finding that, circumstanced as before stated, they would give little or none at the same spot, if the atmosphere above really terminated in a vacuum. I was disappointed in the conclusion, for I obtained as much electricity there as before; but on discovering the action of induction in curved lines (1231.), found a full and satisfactory explanation of the result.

1615. My theory, as far as I have ventured it, does not pretend to decide upon the consequences of a vacuum. It is not at present limited sufficiently, or rendered precise enough, either by experiments relating to spaces void of matter, or those of other kinds, to indicate what would happen in the vacuum case. I have only as yet endeavoured to establish, what all the facts seem to prove, that when electrical phenomena, as those of induction, conduction, insulation and discharge occur, they depend on, and are produced by the action of contiguous particles of matter, the next existing particle being considered as the contiguous one; and I have further assumed, that these particles are polarized; that each exhibits the two forces, or the force in two directions (1295. 1298.); and that they act at a distance only by acting on the contiguous and intermediate particles.

1616. But assuming that a perfect vacuum were to intervene in the course of the lines of inductive action (1304.), it does not follow from this theory, that the particles on opposite sides of such a vacuun could not act on each other. Suppose it possible for a positively electrified particle to be in the centre of a vacuum an inch in diameter, nothing in my present views forbids that the particle should act at the distance of half an inch on all the particles forming the inner superficies of the bounding sphere, and with a force consistent with the well-known law of the squares of the distance. But suppose the sphere of an inch were full of insulating matter, the electrified particle would not then, according to my notion, act directly on the distant particles, but on those in immediate association with it, employing all its power in polarizing them; producing in them negative force equal in amount to its own positive force and directed towards the latter, and positive force of equal amount directed outwards and acting in the same manner upon the layer of particles next in succession. So that ultimately, those particles in the surface of a sphere of half an inch radius, which were acted on directly when that sphere was a vacuum, will now be acted on indirectly as respects 
the central particle or source of action, i. e. they will be polarized in the same way, and with the same amount of force.

\section{$\$$ 19. Nature of the electric current.}

1617. The word current is so expressive in common language, that when applied in the consideration of electrical phenomena we can hardly divest it sufficiently of its meaning, or prevent our minds from being prejudiced by it (283.511.). I shall use it in its common electrical sense, namely, to express generally a certain condition and relation of electrical forces supposed to be in progression.

1618. A current is produced both by excitement and discharge; and whatsoever the variation of the two general causes may be, the effect remains the same. Thus excitement may occur in many ways, as by friction, chemical action, influence of heat, change of condition, induction, \&c.; and discharge has the forms of conduction, electrolyzation, disruptive discharge, and convection; yet the current connected with these actions, when it occurs, appears in all cases to be the same. This constancy in the character of the current, notwithstanding the particular and great variations which may be made in the mode of its occurrence, is exceedingly striking and important; and its investigation and development promise to supply the most open and advantageous road to a true and intimate understanding of the nature of electrical forces.

1619. As yet the phenomena of the current have presented nothing in opposition to the view $I$ have taken of the nature of induction as an action of contiguous particles. I have endeavoured to divest myself of prejudices and to look for contradictions, but I have not perceived any in conductive, electrolytic, convective, or disruptive discharge.

1620. Looking at the current as a cause, it exerts very extraordinary and diverse powers, not only in its course and on the bodies in which it exists, but collaterally, as in inductive or magnetic phenomena.

1621. Electrolytic action.-One of its direct actions is the cxertion of pure chemical force, this being a result which has now been examined to a considerable extent. The effect is found to be constant and definite for the quantity of electric force discharged $(783, \& c$.$) ; and beyond that, the intensity required is in relation to the$ intensity of the affinity or forces to be overcome (904.906.911.). The current and its consequences are here proportionate; the one may be employed to represent the other; no part of the effect of either is lost or gained; so that the case is a strict one, and yet it is the very case which most strikingly illustrates the doctrine that induction is an action of contiguous particles (1164. 1343.).

1622. The process of electrolytic discharge appears to me to be in close analogy, and perhaps in its nature identical with another process of discharge, which at first 
seems very different from it, I mean convection. In the latter case the particles may travel for yards across a chamber; they may produce strong winds in the air, so as to move machinery; and in fluids, as oil of turpentine, may even shake the hand, and carry heavy metallic bodies about*; and yet I do not see that the force, either in kind or action, is at all different to that by which a particle of hydrogen leaves one particle of oxygen to go to another, or by which a particle of oxygen travels in the contrary direction.

1623. Travelling particles of the air can effect chemical changes just as well as the contact of a fixed platina electrode, or that of a combining electrode, or the ions of a decomposing electrolyte (453. 471.); and in the experiment formerly described, where eight places of decomposition were rendered active by one current (469.), and where charged particles of air in motion were the only electrical means of connecting these parts of the current, it seems to me that the action of the particles of the electrolyte and of the air were essentially the same. A particle of air was rendered positive; it travelled in a certain determinate direction, and coming to an electrolyte, communicated its powers ; an equal amount of positive force was accordingly acquired by another particle (the hydrogen), and the latter, so charged, travelled as the former did, and in the same direction, until it came to another particle, and transferred its power and motion, making that other particle active. Now, though the particle of air travelled over a visible and occasionally a large space, whilst the par ticle of the electrolyte moved over an exceedingly small one; though the air particle might be oxygen, nitrogen, or hydrogen, receiving its charge from force of high intensity, whilst the electrolytic particle of hydrogen had a natural aptness to receive the positive condition with extreme facility; though the air particle might be charged with very little electricity at a very high intensity by one process, whilst the hydrogen particle niight be charged with much electricity at a very low intensity by another process; these are not differences of kind, as relates to the final discharging action of these particles, but only of degree; not essential differences which make things unlike, but such differences as give to things, similar in their nature, that great variety which fits them for their office in the system of the universe.

1624. So when a particle of air, or of dust in it, electrified at a negative point, moves on through the influence of the inductive forces (1572.) to the next positive surface, and after discharge passes away, it seems to me to represent exactly that particle of oxygen which, having been rendered negative in the electrolyte, is urged by the same disposition of inductive forces, and going to the positive platina electrode, is there discharged, and then passes away, as the air or dust did before it.

* If a metallic ressel three or four inches deep, containing oil of turpentine, be insulated and electrified, and a rod with a ball (an inch or more in diameter) at the end have the ball immersed in the fluid whilst the end is held in the hand, the mechanical force generated when the ball is moved to and from the sides of the vessel will soon be evident to the experimenter. 
1625. Heat is another direct effect of the current upon substances in which it occurs, and it becomes a very important question, as to the relation of the electric and heating forces, whether the latter is always definite in amount*. There are nıany cases, even amongst bodies which conduct without change, which stand out at present from the assumption that it is $\gamma$; but there are also many which indicate that, when proper limitations are applicd, the heat produced is definite. Harris has shown this for a given length of current in a metallic wire, using common electricity DE LA Rrve has proved the same point for voltaic electricity by his beautiful application of BrEgueT's thermometer $\oint$.

1626. When the production of heat is observed in electrolytes under decomposition, the results are still more complicated. But important steps have been taken in the investigation of this branch of the subject by DE LA RIVE $\|$ and others; and it is more than probable tliat, when the right limitations are applied, constant and definite results will here also be obtained.

1627. It is a most important part of the character of the current, and essentially connected with its very nature, that it is always the same. The two forces are everywhere in it. There is never one current of force or one fluid only. Any one part of the current may, as respccts the presence of the two forces there, be considered as preciscly the same with any other part; and the numerous experiments which imply their possible separation, as well as the theoretical expressions which, being uscd daily, assume it, are, I think, in contradiction with facts (5 1 1, \&c.). It appears to mc to be as impossible to assume a current of positive or a current of negative force alone, or of the two at once with any predominance of one over the other, as it is to give an absolute charge to matter (1169.1177.).

1628. The conviction of this truth, if, as I think, it be a truth, or on the other hand the disproof of it, is of the greatest consequence. If, as a first principle, we can establish that the centres of the two forces, or elements of force, never can be separated to any sensiblc distance, or at all events not further than the space between two contiguous particles (1615.), or if we can establish the contrary conclusion, how much more clear is our view of what lies before us, and how much less embarrassed the ground over which we have to pass in attaining to it, than if we remain lalting between two opinions! And if, with that feeling, we rigidly test every experiment which bears upon the point, as far as our prejudices will let us (1161.), instead of permitting them with a theoretical expression to pass too easily away, are we not

* See De ra Rive's Researches, Bib. Universelle, 1829, xl. p. 40.

$\dagger$ Amongst others, $D_{A v Y}$, Philosophical Transactions, 1821, p. 438. Pelletier's important results, Annales de Chimie, 1834, lvi. p. 371. and Becquerex's non-heating current, Bib. Universelle, 1835, lx. 218.

†Philosophical Transactions, 1824, pp. 225, 228.

§ Annales de Chimie, 1836, lxii. 177.

If Bib. Universelle, 1829, xl. 49; and RItchIE, Phil. Trans. 1832, p. 296. 
much more likely to attain the real truth, and fiom that procced with safety to what is at present unknown?

1629. I say these things not, I hope, to advance a particular view, but to draw the strict attention of those who are able to investigate and judge of the matter, to what must be a turning point in the theory of electricity; to a separation of two roads, one only of which can be right: and I hope I may be allowed to go a little further into the facts which have driven me to the view $I$ have just given.

1630. When a wire in the voltaic circuit is heated, the temperature frequently rises first, or most at one end. If this effect were due to any relation of positive or negative as respects the current, it would be exceedingly important. I therefore examined several such cases; but when, keeping the contacts of the wire and its position to neighbouring things unchanged, I altered the direction of the current, I found that the effect remained unaltered, showing that it depended, not upon the direction of the current, but on other circumstances. So there is here no evidence of a difference between one part of the circuit and another.

1631. The same point, i. e. uniformity in every.part, may be illustrated by what may be considered as the inexhaustible nature of the current when producing particular effects; for these effects depend upon transfer only, and do not consume the power. Thus a current which will heat one inch of platina wire will heat a hundred inches (853. note). If a current be sustained in a constant state, it will decompose the fluid in one voltameter only, or in twenty others if they be placed in the circuit, in each to an amount equal to that in the single one.

1632. Again, in cases of disruptive discharge, as in the spark, there is frequently a dark part (1422.), which, by Professor Johnson, has been called the neutral point*; and this has given rise to the use of expressions implying that there are two electricities existing separately, which, passing to that spot, there combine and neutralize each other $\downarrow$. But if such expressions are understood as correctly indicating that positive electricity alone is moving between the positive ball and that spot, and negative electricity only between the negative ball and that spot, then what strange conditions these parts must be in; conditions, which to iny mind are every way unlike that which really occurs! In such a case, one part of a current would consist of positive electricity only, and that moving in one direction; another part would consist of negative electricity only, and that moving in the other direction; and a third part would consist of an accumulation of the two electricities, not moving in either direction, but mixing up together, and being in a relation to each other utterly unlike any relation which could be supposed to exist in the two former portions of the discharge. This does not seem to me to be natural. In a current, whatever form the discharge may take, or whatever part of the circuit or current is referred to, as much positive force as is there exerted in one direction, so much negative force is there exerted in the other. If it were not so we should have bodies electrified not merely

* Silnimay's Journal, 1834, xxv. p. 57.

+ Thomson on Heat and Electricity, p. 471. 
positive and negative, but on occasions in a most extraordinary manner, one being charged with five, ten, or twenty times as much of both positive and negative electricity in equal quantities as another. At present, however, there is no known fact indicating such states.

1633. Even in cases of convection, or carrying discharge, the statement that the current is everywhere the same must in effect be true (1627.): for how, otherwise, could the results formerly described occur? When currents of air constituted the mode of discharge between the portions of paper moistened with iodide of potassium or sulphate of soda (465. 469.), decomposition occurred; and I have since ascertained that, whether a current of positive air issued from a spot, or one of negative air passed towards it, the effect of the evolution of iodine or of acid was the same, whilst the reversed currents produced alkali. So also in the magnetic experiments (307.) whether the discharge was effected by the introduction of a wire, or the occurrence of a spark, or the passage of convective currents either one way or the other, (depending on the electrified state of the particles) the result was the same, being in all cases dependent upon the perfect current.

1634. Hence, the section of a current compared with other sections of the same current inust be a constant quantity, if the actions exerted be of the same kind; or if of different kinds, then the forms under which the effects are produced are equivalent to each other, and experimentally convertible at pleasure. It is in sections, therefore, we must look for identity of electrical force, even to the sections of sparks and carrying actions, as well as those of wires and electrolytes.

1635. In illustration of the utility and importance of establishing that which inay be the true principle, I will refer to a few cases. 'The doctrine of unipolarity as formerly stated, and I think generally understood*, is evidently inconsistent with ny view of a current (1627.); and the later singular phenomena of poles and flames described by Erman and others $f$ partake of the same inconsistency of character. If a unipolar body could exist, $i$. e. one that could conduct the one electricity and not the other, what very new characters we should have a right to expect in the currents of single electricities passing through them, and how greatly ought they to differ, not only from the common current which is supposed to have both electricities travelling in opposite directions in equal amount at the same time, but also from each other! 'The facts, which are excellent, have, however, gradually been more correctly explained by Becquerel $*$, Andrews $\oint$, and others; and I understand that Professor OHмs \| has perfected the work, in his close examination of all the phenomena; and

* Ermax, Annales de Chimie, 1807. lxi. p. 115. Davy's Elements, p. 168. Brot, Ency. Brit. Supp. iv. p. 444. Becquered, Traité, i. p. 167. De la Rive, Bib. Univ. 1837. vii. 392.

$\uparrow$ Erman, Annales de Chimie, 1824. xxv. 278. Becquerel, Ibid, xxxvi. p. 329.

‡ Becquerel, Annales de Chimie, 1831. xlvi. p. 283.

$\$$ Andrews, Philosophical Magazine, 1836. ix. 182.

॥ SchWe1Gger's Jahrbuch der Chemie, \&c. 1830. Heft 8. Not understanding German, it is with extreme 
after showing that similar phenomena can take place with good conductors, proves that with soap, \&c. many of the effects are the mere consequences of the bodies evolved by electrolytic action.

1636. I conclude, therefore, that the facts upon which the doctrine of unipolarity was founded are not adverse to that unity and indivisibility of character which I have stated the current to possess, any more than the phenomena of the pile itself, which might well bear comparison with those of unipolar bodies, are opposed to it. Probably the effects which have been called effects of unipolarity, and the peculiar differences of the positive and negative surface when discharging into air, gases, or other dielectrics (1480.1525.) which have been already referred to, may have considerable relation to each other*.

1637. M. DE LA RIVE has recently described a peculiar and remarkable effect of heat on a current when passing between electrodes and a fluid $\gamma$. It is, that if platina electrodes dip into acidulated water no change is produced in the passing current by making the positive electrode hotter or colder; whereas making the negative electrode hotter increased the deflexion of a galvanometer affected by the current, from $12^{\circ}$ to $30^{\circ}$ and even $45^{\circ}$, whilst making it colder diminished the current in the same high proportions.

1638. That one electrode should have this striking relation to heat whilst the other remained absolutely without, seem to me as incompatible with what I conceived to be the character of a current as unipolarity (1627.1635.), and it was therefore with some anxiety that I repeated the experinent. The electrodes which I used were of platina; the electrolyte, water containing about one sixth of sulphuric acid by weight: the voltaic battery consisted of two pairs of amalgamated zinc and platina plates in dilute sulphuric acid, and the galvanometer in the circuit was one with two needles, and gave when the arrangement was complete a deflexion of $10^{\circ}$ or $12^{\circ}$.

1639. Under these circumstances heating either electrode increased the current; heating both produced still more effect. When both were heated, if either were cooled, the effect on the current fell in proportion. The proportion of effect due to heating this or that electrode varied, but on the whole heating the negative seemed to favour the passage of the current somewhat more than heating the positive.

regret $I$ confess $I$ have not access, and cannot do justice, to the many most valuable papers in experimental electricity published in that language. I take this opportunity also of stating another circumstance which occasions me great trouble, and, as I find by experience, may make me seemingly regardless of the labours of others :-it is a gradual loss of memory for some years past; and now, often when I read a memoir, I remember that I have seen it before, and would have rejoiced if at the right time I could have recollected and referred to it in the progress of my own papers.-M. F.

* See also HARE in Silliman's Journal, 1833. xxiv. 246.

† Bibliothèque Universelle, 1837. vii. 388.

MDCCCXXXVIII. 
Whether the application of heat werc by a flame applied underneath, or one directed by a blow pipe from above, or by a hot iron or coal, the effect was the same.

1640. Having thus removed the difficulty out of the way of my views regarding a current, I did not pursue this curious experiment further. It is probable, that the difference between my results and those of M. DE LA RIVE may depend upon the relative values of the currents used; for I employed only a weak one resulting from two pairs of plates two inches long and half an inch wide, whilst M. DE LA Rive used four pairs of plates of sixteen square inches in surface.

1641. Electric discharges in the atmosphere in the for'm of balls of fire have occasionally been described. Such phenomena appcar to me to bc incompatible with all that we know of electricity and its modes of discharge. As time is an element in the effcct (1418. 1436.) it is possible perhaps that an electric discharge might really pass as a ball from place to place; but as every thing shows that its velocity must be alınost infinite, and the time of its duration exceedingly small, it is impossible that the eye should perceive it as anything else than a line of light. That phenomena of balls of fire may appear in the atmosphere, I do not mean to deny; but that they have anything to do with the discharge of ordinary electricity, or arc at all related to lightning or atmospheric electricity, is much more than doubtful.

1642. All these considerations, and inany others, help to confirm the conclusion, drawn over and over again, that the current is an indivisible thing; an axis of power, in evcry part of which both electric forccs are present in equal amount* (517. 1627.). With conduction and electrolyzation, and even discharge by spark, such a view will harmonize without hurting any of our preconceived notions; but as relates to convection, a more startling rcsult appears, which must thercfore be considered.

1643. If two balls $A$ and $B$ be electrified in opposite states and held within each other's influence, the moment they move towards each other, a current, or those effects which are understood by the word current, will be produced. Whether A move towards B, or $\mathbf{B}$ move in the opposite direction towards $\mathbf{A}$, a current, and in both cases having the same direction, will result. If $\mathbf{A}$ and $\mathbf{B}$ move from cach other, then a current in the oppositc direction, or equivalent effccts, will be produced.

1644. Or, as charge exists only by induction (1178. 1299.), and a body when electrified is necessarily in relation to other bodies in the opposite. state; so, if a ball be electrified positively in the middle of a room and be then moved in any direction, effects will be produced, as if a current in the same direction (to use the conventional

* I am glad to refer here to the results obtained by Mr. Christre with magneto-electricity, Philosophical Transactions, 1833, p. 113. note. As regards the current in a wire, they confirm everything that I am contending for. 
modc of expression) had existed: or, if the ball be negativcly elcctrified, and then moved, effects as if a current in a dircction contrary to that of the motion had been fornied, will be produced.

1645. I am saying of a single particle or of two what I have before said, in effect, of many (1633.). If the former account of currents be true, then that just stated must be a necessary result. And, though the statement may seem startling at first, it is to be considered that, according to my theory of induction, the charged conductor or particle is related to the distant conductor in thc opposite state, or that which terminates the extent of the induction, by all the intermediate particles (1165. 1295.), these becoming polarized exactly as the particlcs of a solid electrolyte do when interposed between the two electrodes. Hence the conclusion regarding the unity and identity of the current in the case of convection, jointly with the former cases, is not so strange as it might at first appear.

1646. There is a very remarkable phenomenon or effect of the electrolitic discharge, first pointed out, I believe, by Mr. Porrert, of the accumulation of fluid under decomposing action in the current on one side of an interposed diaphragm*. It is a mechanical result; and as the liquid passes from thc positive towards the negative electrode in all the known cases, it seems to establish a relation to the polar condition of the dielectric in which the current exists (1164.1525.). It has not as yet been sufficiently investigated by experiment; for De LA Rive says $\downarrow$, it requires that the water should be a bad conductor, as, for instance, distilled water, the effect not happening with strong solutions; whereas, Dutrochet says $*$ the contrary is the case, and that, the effect is not directly due to the electric current.

1647. Becquereu in his Traité de l'Electricité has brought together the considerations which arise for and against the opinion, that the effect generally is an electric effect $\S$. Though I have no decisive fact to quote at present, I cannot refrain from venturing an opinion, that the effect is analogous both to combination and convection (1623.), being a case of carrying due to the relation of the diaphragm and the fluid in contact with it, through which the clectric discharge is jointly effected; and further, that the peculiar relation of positive and negative small and large surfaces already referred to (1482.1503.1525.), may be the direct cause of the fluid and the diaphragm travelling in contrary but determinate directions. A very valuable experiment has been made by M. Becqueres with particlcs of clay\|, which will probably bear importantly on this point.

\footnotetext{
* Annals of Philosophy, 1816. viii. p. 75.

+ Annales de Chimie, 1832. xlix. p. 423.

\| Traité de l'Electricité, i. p. 285.
}

† Annales de Chimie, 1835. xxviii. p. 196.

\$ol.iv. p. 197. 192. 
1648. As long as the terms current and electro-dynamic are used to express those relations of the electric forces in which progression of either fluids or effects are supposed to occur (283.), so long will the idea of velocity be associated with them; and this will, perhaps, be more especially the case if the hypothesis of a fluid or fluids be adopted.

1649. Hence has arisen the desire of estimating this velocity either directly or by some effect dependent on it; and amongst the endeavours to do this correctly, may be mentioned especially those of Dr. Watson* in 1748, and of Professor Wheatstone $\uparrow$ in 1834 ; the electricity in the early trials being supposed to travel from end to end of the arrangement, but in the later investigations a distinction occasionally appearing to be made between the transmission of the effect and of the supposed fluid by the motion of whose particles that effect is produced.

1650. Electrolytic action has a remarkable bearing upon this question of the velocity of the current, especially as connected with the theory of an electric fluid or fluids. In it there is an evident transfer of power with the transfer of each particle of the anion or cathion present, to the next particles of the cathion or anion; and as the amount of power is definite, we have in this way a means of localizing as it were the force, identifying it by the particle and dealing it out in successive portions, which leads, I think, to very striking results.

1651. Suppose, for instance, that water is undergoing decomposition by the powers of a voltaic battery. Fach particle of hydrogen as it moves one way, or of oxygen as it moves in the other direction, will transfer a certain amount of electrical force associated with it in the form of chemical affinity (822. 852.918.) onwards through a distance, which is equal to that through which the particle itself has moved. This transfer will be accompanied by a corresponding movement in the electrical forces throughout every part of the circuit formed (1627. 1634.), and its effects may be estimated, as, for instance, by the heating of a wire (853.) at any particular section of the current however distant. If the water be a cube of an inch in the side, the electrodes touching, each by a surface of one square inch, and being an inch apart, then, by the time that a tenth of it, or $25 \cdot 25$ grains, is decomposed, the particles of oxygen and hydrogen throughout the mass may be considered as having moved relatively to each other in opposite directions, to the anount of the tenth of an inch; i. e. that two particles at first in combination will after the motion be the tenth of an inch apart. Other motions which occur in the fluid will not at all interfere with this result; for they have no power of accelerating or retalding the electric discharge, and possess in fact no relation to it.

1652. 'The quantity of electricity in 25.25 grains of water is, according to an estimate of the force which I formerly made (861.), equal to above 24 millions of charges of a large Leyden battery; or it would have kept any length of a platina wire $\frac{1}{10} \frac{1}{4}$ an inch in diameter red bot for an hour and a half (853.). 'This result, though given 
only as an approximation, I have seen no reason as yet to alter, and it is confirmed generally by the experiments and results of M. Poulllet*. According to Mr. Wheat STONE's experiments the influence or effects of the current would appear at a distance of 576,000 miles in a second $\downarrow$. We have, therefore, in this view of the matter, on the one hand, an enormous quantity of power equal to a most destructive thunder storm appearing instantly at the distance of 576,000 miles from its source, and on the other, a quiet effect, in producing which the power had taken an hour and a half to travel through the tenth of an inch : yet these are the equivalents to each other, being effects observed at the sections of one and the same current (1634.).

1653. It is time that $I$ should call attention to the lateral or transverse forces of the current. The great things which have been achieved by Oersted, Arago, Ampere, Davy, De LA Rive, and others, and the high degree of simplification which has been introduced into their arrangement by the theory of AMPERE, have not only done their full service in advancing most rapidly this branch of knowledge, but have secured to it such attention that there is no necessity for urging on its pursuit. I refer of course to magnetic action and its relations; but though this is the only recognised lateral action of the current, there is great reason for believing that others exist and would by their discovery reward a close search for them (951.).

1654. The magnetic or transverse action of the current seems to be in a most extraordinary degree independent of those variations or modes of action which it presents directly in its course; it consequently is of the more value to us, as it gives us a higher relation of the power than any that might have varied with each mode of discharge. This discharge, whether it be by conduction through a wire with infinite velocity (1652.), or by electrolyzation with its corresponding and exceeding slow motion (1651.), or by spark, and probably even by convection, produces a transverse magnetic action always the same in kind and direction.

1655. It has been shown by several experimenters, that whilst the discharge is of the same kind the amount of lateral or magnetic force is very constant (366. 367. 368 . 376.). But when we wish to compare discharge of different kinds, for the important purpose of ascertaining whether the same amount of current will in its different forms produce the same amount of transverse action, we find the data very inperfect. DAvy noticed, that when the electric current was passing through an aqueous solution it affected a magnetic needle ${ }_{+}^{*}$, and Dr. Ritchie says, that the current in the electrolyte is as magnetic as that in a metallic wire $\S$, and has made water revolve round a magnet as a wire carrying the current would revolve.

1656. Disruptive discharge produces its magnetic effects : a strong spark, passed

* Becquerre, Traité de l'Electricité, v. p. 278.

$\ddagger$ Philosophical Transactions, 1821, p. 426 . $\uparrow$ Philosophical Transactions, 1834, p. 589.

Ibid. 1832, p. 294. 
transverscly to a steel nsedle, will magnetise it as well as if the electricity of the spark werc conducted by a metallic wirc occupying the line of discharge; and Sir H. DAvy has shown that the discharge of a voltaic battery in vacuo is affected and has motion given to it by approximated magnets*.

1657. Thus the three very different nodes of discharge, namely, conduction, electrolyzation, and disruptive dischargc, agree in producing the important transverse phenomenon of magnetism. Whether convection or carrying discharge will produce the same phenomenon has not been determined, and the few experiments $I$ have as yet had time to nlakc do not enable me to answer in the affirmative.

1658. Having arrived at this point in the consideration of the current and in the endeavour to apply its phenomena as tests of the truth or fallacy of the theory of induction which I have ventured to set forth, I am now very much tempted to indulge in a few speculations respecting its lateral action and its possiblc connexion with the transverse condition of the lines of ordinary induction (1 165. 1304.). I have long sought and still seck for an effect or condition which shall be to statical electricity what magnetic force is to current clectricity; for as the lines of discharge are associated with a certain transverse effect, so it appeared to me impossible but that the lines of tension or of inductive action, which of necessity precede that discharge, should also have their correspondent transverse condition or effect (951.).

1659. According to the beautiful thcory of AMPERE, the transvcrse force of a current may be represented by its attraction for a similar current and its repulsion of a contrary current. May not then the equivalent transverse force of static elcctricity be represented by that lateral tension or repulsion which the lines of inductive action appear to possess (1304.) ? 'Then again, when current or discharge occurs between two bodies, previously under inductrical relations to each other, the lines of inductive force will weaken and fade away, and, as their latcral repulsive tension diminishes, will contract and ultimately disappear in the line of discharge. May not this be an effect identical with the attractions of similar currents? i. e. may not the passagc of static clectricity into current electricity, and that of the lateral tension of the lines of inductive force into the lateral attraction of lines of similar discharge, have the same relation and depcndencies, and run parallel to each other?

1660. The phenomena of induction amongst currents which I had the good fortune to discover some year's ago (6. \&c. 1048.) may perchance here form a connecting link in the series of effects. When a current is first formed, it tends to produce a current in the contrary direction in all the matter around it; and if that matter have conducting properties and be fitly circumstanced, such a current is produced. On the contrary, when the original current is stopped, onc in the same direction tends to form all around it, and, in conducting matter propcrly arranged, will be excited. 
1661. Now though we perceive the effects only in that portion of inatter which, being in the neighbourhood, has conducting properties, yet hypothetically it is probable, that the non-conducting matter has also its relations to, and is affected by, the disturbing cause, though we have not yet discovered them. Again and again the relation of conductors and non-conductors has been shown to be one not of opposition in kind, but only of degree (1334. 1603.); and, thcrefore, for this, as well as for other reasons, it is probable, thai what will affect a conductor will affect an insulator also; producing perhaps what may deserve the term of the electrotonic state 60 . 242. 1114).

1662. It is the feeling of the necessity of some lateral connexion between the lines of electric force (1114.); of some link in the chain of effects as yet unrecognised, that urges me to the expression of these speculations. The same feeling has led me to make many experiments on the introduction of insulating dielectrics having different inductive capacities (1270.1277.) bctween magnetic poles and wires carrying currents, so as to pass across the lines of magnetic force. I have employed such bodies both at rest and in motion, without, as yet, being able to detect any influence produced by them; but I do by no means consider the experiments as sufficiently delicate, and intend, very shortly, to render them more decisive.

1663. I think the hypothetical question nay at present be put thus : can such considerations as those already generally expressed (1658.) account for the transverse effects of electrical currents? are two such currents in relation to each other merely by the inductive condition of the particles of matter between them, or are they in relation by some higher quality and condition (1654.), which, acting at a distance and not by the intermediate particles, has, like the force of gravity, no relation to them?

1664. If the latter be the case, then, when electricity is acting upon and in matter, its direct and its transverse action are essentially different in their nature; for the former, if I am correct, will depend upon the contiguous particles, and the latter will not. As I have said before, this may be so, and I incline to that view at present, but I am desirous of suggesting considerations why it may not, that the question may be thoroughly sifted.

1665. 'The transverse power has a character of polarity impressed upon it. In the sinplest forms it appears as attraction or repulsion, according as the currents are in the same or different directions: in the current and the magnet it takes up the condition of tangential forces; and in magnets and their particles produces poles. Since the experiments have been made which have persuaded me that the polar forces of electricity, as in induction and electrolytic action (1298. 1343.), show effects at a distance only by means of the polarized contiguous and intervening particles, I have been led to expect that all polur forces act in the same general manner ; and the other kinds of phenomena which one can bring to bear upon the subject seem fitted to strengthen that expectation. Thus in crystallizations the effect is transinitted from 
particle to partiele; and in this manner, in acetie acid or freezing water a crystal a few inches or even a couple of feet in length will form in less than a second, but progressively and by a transmission of power from partiele to particle. And, as far as I remember, no case of polar action, or partaking of polar action, except the one under discussion, can be found which does not act by contiguous particles*. It is apparently of the nature of polar forces that such should be the case, for the one foree either finds or developes the eontrary force near to it, and has, therefore, no oeeasion to seek for it at a distanee.

1666. But leaving these hypothetieal notions respecting the nature of the lateral action out of sight, and returning to the direct effects, I think that the phenomena examined and reasoning employed in this and the two preceding papers tend to eonfirm the view first taken (1164.), namely, that ordinary inductive action and the effects dependent upon it, are due to an action of the contiguous particles of the dieleetric interposed between the charged surfaces or parts which constitute, as it were, the terminations of the effect. The great point of distinction and power (if it have any) in the theory is, the making the dielectric of essential and specific importance, instead of leaving it as it were a mere aecidental circumstance or the simple representative of space, having no more influence over the phenomena than the space oeeupied by it. I have still eertain other results and views respecting the nature of the electrical forces and excitation, which are eonneeted with the present theory; and, unless upon further consideration they sink in my estimation, I shall very shortly put them into form as another series of these eleetrieal researches.

* I mean by contiguous particles those which are next to each other, not that there is no space between them. See (16]6.).

Royal Institution, February 14th, 1838. 


